\title{
Design Science Research: método de pesquisa para a engenharia de produção
}

\author{
Design Science Research: a research method to \\ production engineering
}

\author{
Daniel Pacheco Lacerda ${ }^{1}$ \\ Aline Dresch ${ }^{1}$ \\ Adriano Proença ${ }^{2}$ \\ José Antonio Valle Antunes Júnior ${ }^{1}$
}

\begin{abstract}
Resumo: Para garantir que uma pesquisa seja reconhecida como sólida e potencialmente relevante, tanto pelo campo acadêmico quanto pela sociedade em geral, ela deve demonstrar que foi desenvolvida com rigor e que é passível de debate e verificação. É neste âmbito que um método de pesquisa robusto se torna imprescindível para o sucesso na condução de um estudo. Este artigo busca contribuir para a comunidade de Engenharia de Produção argumentando pela necessidade de adotar-se um método de pesquisa centrado na evolução de uma "Ciência do Projeto" (Design Science) da área, e evidenciando seu sentido e suas formas de operacionalização. Para desenvolvimento deste artigo, utilizou-se a abordagem metodológica teórico-conceitual fundamentada em ampla revisão da literatura. A partir da revisão da literatura, foi possível verificar que os conceitos da proposta metodológica associada à pesquisa em Design Science, são pertinentes e aplicáveis à Engenharia de Produção. O artigo apresenta um histórico conceitual a respeito da Design Science e da Design Science Research, a importância da definição das Classes de Problemas e dos Artefatos gerados no âmbito da pesquisa, e os principais passos para operacionalizar a Design Science Research. Para aprofundar o entendimento da pauta em questão, o artigo também propõe comparações e análises sobre a Design Science Research, o Estudo de Caso e a Pesquisa-Ação, dado que os dois últimos são reconhecidos como métodos de pesquisa no âmbito da Engenharia de Produção nacional. Ao final, o estudo busca apresentar alguns cuidados para a aplicação e validação da Design Science Research.
\end{abstract}

Palavras-chave: Método. Design Research. Design Science. Pesquisa. Design Science Research.

\begin{abstract}
This paper aims to contribute to the Brazilian community of Production Engineering addressing the need to adopt a research strategy focused on the evolution of Production Engineering as a Design Science (DS) showing its effects and process. A theoretical and conceptual methodological approach based on an extensive literature review was used. The literature review showed that the concepts of the methodology proposed associated to Design Science Research (DSR) are relevant and can be applied to Production Engineering. The present study presents a review of DS and DSR concepts stressing the importance of defining the classes of problems and the artifacts to solve them. It also suggests appropriate steps to conduct DSR in Production Engineering context. To deepen the understanding of the meaning of DSR, this article also makes analyses and comparisons between DSR, Case Study, and Action Research in order to clarify the main differences between these methods. Finally, this study makes some remarks on the application of DSR methods and the validation of DSR results.
\end{abstract}

Keywords: Method. Design Research. Design Science. Research. Design Science Research.

\section{Introdução}

Segundo Popper (2006, p. 61), "As teorias são redes, lançadas para capturar aquilo que denominamos mundo: para racionalizá-lo, explicá-lo, dominá-lo.” Na base da construção das teorias, estão os métodos científicos de pesquisa. Os métodos de pesquisa consistem em um conjunto de regras e procedimentos, aceitos pela comunidade acadêmica, para a construção do conhecimento científico (ANDERY et al., 2004). De fato

\footnotetext{
${ }^{1}$ Programa de Pós-graduação em Engenharia de Produção e Sistemas - PPGEPS, Universidade do Vale do Rio dos Sinos - UNISINOS, CEP 93022-000, São Leopoldo, RS, Brasil, e-mail: dlacerda@unisinos.br; aldresch@gmail.com; junico@ produttare.com.br

2 Instituto Alberto Luiz Coimbra de Pós-graduação e Pesquisa de Engenharia - COPPE, Universidade Federal do Rio De Janeiro - UFRJ, CEP 21941-972, Rio de Janeiro, RJ, Brasil, e-mail: adriano.proenca@gpi.ufrj.br
}

Recebido em 12/9/2012 — Aceito em 5/8/2013

Suporte financeiro: CAPES (Coordenação de Aperfeiçoamento de Pessoal de Nível Superior) por meio do projeto MGOOI (Modelo de Gestão de Operações em Organizações Inovadoras) do Pró-engenharias. 
[...] os métodos de pesquisa moldam a linguagem que utilizamos para descrever o mundo, e a linguagem molda como nós pensamos sobre o mundo [...] (BENBASAT; WEBER, 1996, p. 392).

Portanto, possuir um repertório amplo e bem definido de métodos de pesquisa pode contribuir para o avanço da teoria e, por consequência, do conhecimento em determinada área.

Este artigo tem como enfoque principal a Engenharia de Produção, que, no Brasil, caracteriza-se por apresentar uma interface significativa com outras áreas do conhecimento, como a administração, a economia e a gestão de operações, em particular (THIOLLENT; ALVEAR, 2009). Tanto na Engenharia de Produção (NAKANO, 2010; MIGUEL, 2007; BERTO; NAKANO, 1998) quanto na área de Gestão de Operações (SLACK; LEWIS; BATES, 2004; CRAIGHEAD; MEREDITH, 2008; TAYLOR; TAYLOR, 2009) há a preocupação em caracterizar os métodos de pesquisa apropriados e clamar por maior rigor na condução das pesquisas na área.

Em extensiva pesquisa sobre métodos de pesquisa adotados no âmbito dos principais periódicos internacionais da área de gestão de operações, Craighead e Meredith (2008) apontam como resultado: i) a predominância do paradigma positivista/ empiricista; ii) a estabilização da pesquisa envolvendo modelagem/simulação; iii) crescimento das pesquisas de cunho interpretativista. No Brasil, em análise nos anais do ENEGEP (Encontro Nacional de Engenharia de Produção), pode-se verificar: i) predominância dos estudos de caso; ii) predominância dos estudos empíricos; iii) reduzida participação relativa das surveys; e iv) pouca aplicação da modelagem e da simulação computacional (NAKANO, 2010).

Os trabalhos que procuram discutir a pesquisa nas áreas de Gestão de Operações e de Engenharia de Produção têm tipicamente considerado como referência os objetivos e práticas de pesquisa das ciências naturais e sociais. Segundo Van Aken (2004) e Romme (2003), de fato a maior parte das pesquisas em gestão é fundamentada na noção de que o objetivo da ciência é descrever, entender, explicar e, se possível, predizer. Por consequência, seu principal foco é desenvolver pesquisas que permitam a construção de teorias que descrevam, expliquem e predigam como a realidade, em geral, e os processos empresariais, em particular, funcionam (NAKANO, 2010; CRAIGHEAD; MEREDITH, 2008; TAYLOR; TAYLOR, 2009). Portanto, para que haja maior confiabilidade das teorias propostas, é necessário avançar o rigor metodológico, principalmente em questões de validade (MENTZER; FLINT, 1997; WORREN; MOORE; ELLIOTT, 2002; VAN AKEN, 2005).

No entanto, essa visão sobre a forma de construção de conhecimento científico aplicada ao campo da gestão, em geral, e da gestão de operações, em particular, tem recebido um conjunto significativo de críticas. Hambrick (2007), por exemplo, argumenta que o excessivo foco em teorias descritivas tem dificultado o desenvolvimento de trabalhos que abram novas perspectivas em termos de pesquisas futuras. Ao mesmo tempo, há um paradoxo entre o avanço na sofisticação dos métodos e técnicas de pesquisa e sua capacidade de resolver problemas práticos (RYNES; BARTUNEK; DAFT, 2001; WORREN; MOORE; ELLIOTT, 2002; GUIDE; VAN WASSENHOVE, 2007).

Argumenta-se que há necessidade de maior relevância das pesquisas na área de gestão, do ponto de vista das organizações (STARKEY; MANDAN, 2001; RYNES; BARTUNEK; DAFT, 2001; FORD et al., 2003). Platts (1993), por exemplo, traz a discussão da relevância entre teoria e prática para a área de operações. A discussão de Platts (1993) reconhece a necessidade das organizações aperfeiçoarem seus processos, mas que nem sempre os resultados das pesquisas acadêmicas, por meio dos métodos tradicionais, trazem uma contribuição adequada.

Nesse sentido, Gouvêa da Costa e Pinheiro de Lima (2011), apoiados em Platts et al. (1998) e Platts (1993), explicitam a distinção entre o conhecimento científico e o conhecimento em engenharia. A Engenharia se preocupa com a utilização do conhecimento científico com o objetivo de projetar e construir artefatos para a solução dos problemas (GOUVÊA DA COSTA; PINHEIRO DE LIMA, 2011). Dessa forma, Gouvêa da Costa e Pinheiro de Lima (2011) propõem a Abordagem por Processos (Process Approach ou Cambridge Approach) como uma alternativa que intenciona a prescrição e a operacionalização dos conceitos.

Este artigo procura recolocar os termos destas questões sob outro enfoque. Ele parte do conceito de "Ciência do Artificial" ou "Ciência do Projeto" - Design Science (DS) (SIMON, 1996) e do método que a constrói, a "pesquisa em Ciência do Projeto", ou "Design Science Research" (MARCH; SMITH, 1995; CANTAMESSA, 2003; HEVNER; MARCH; PARK, 2004; MANSON, 2006; JÄRVINEN, 2007). A partir deste enfoque, procurar-se-á apresentar como se conduziria a pesquisa em Engenharia, em geral, e em Engenharia de Produção e Gestão de Operações, em particular.

Trata-se de buscar contribuir para a instrumentação conceitual e epistemológica da comunidade científica da Engenharia de Produção brasileira. Primeiro, somando-se aos esforços de conscientização da necessidade e legitimidade de pesquisas em DS/DR (BAYAZIT, 2004). Segundo, juntando-se ao clamor pela necessidade, tal como exposta por Miguel (2007), de mobilizar esforços para o estudo de métodos apropriados e efetivos para a Engenharia de 
Produção. Terceiro, alinhando-se à busca por ampliar as possibilidades de enquadramento metodológico das pesquisas em Engenharia de Produção. Pesquisas que se dedicam à construção de artefatos devem poder se sustentar como válidas cientificamente com uma abordagem metodológica rigorosa e apropriada. Por fim, por propor a discussão das possibilidades de avanço do conhecimento, em geral, e do tecnológico, em particular, na área de Engenharia de Produção, a partir de seu entendimento como uma Design Science.

Este artigo adota uma abordagem metodológica teórico-conceitual fundamentada em revisão da literatura, buscando construir uma proposição geral quanto a como se conduzir uma pesquisa no contexto da Design Science Research. Seu objetivo é sintetizar os procedimentos e pontos a serem observados na realização de pesquisas no contexto da DS/DSR.

Inicialmente recupera-se a histórica e demarcam-se os principais conceitos associados à Design Science. Na sequência, aprofunda-se a discussão em torno da importância da definição de Classes de Problemas e na tipologia geral de Artefatos (concepções centrais para a Design Science e a Design Science Research). Em seguida, desdobra-se a forma de operacionalização da Design Science Research na condução de pesquisas. Como exercício complementar, pertinente em particular para a situação da Engenharia de Produção brasileira, o artigo se dedica à comparação entre a Design Science Research e os métodos do Estudo de Caso e da Pesquisa-Ação, buscando elucidar suas principais distinções. Por fim, expõem-se alguns cuidados para a validade da pesquisa em Design Science Research com vistas a robustecer a avaliação dos artefatos e, por consequência, do conhecimento gerado.

\section{Histórico e contextualização da Design Science}

A distinção entre os ambientes natural e artificial é realizada originalmente por Herbert Simon (1969, 1996). Segundo Simon (1996), a ciência natural se refere a um conjunto de conhecimentos sobre uma classe de objetos e/ou fenômenos do mundo (suas características, como se comportam e como interagem). Nesse sentido, é tarefa das disciplinas científicas naturais pesquisarem e ensinarem como as coisas são e como elas funcionam. Esse raciocínio pode ser aplicado para os fenômenos naturais (biologia, química, física) e sociais (economia, sociologia).

No entanto, Simon (1996) levanta a possibilidade de estudos sobre o universo "artificial", definindo que as "ciências do artificial" se ocupam da "concepção de artefatos que realizem objetivos" (SIMON, 1996, p. 198). Ou seja, as ciências do artificial dizem respeito a como as coisas devem ser para funcionar e atingir determinados objetivos. Tem sido, justamente, a tarefa das escolas de engenharia, por exemplo, ensinar o que se refere ao artificial: como criar e projetar artefatos que tenham as propriedades desejadas e alcancem objetivos definidos (SIMON, 1996).

Em uma leitura superficial, as ciências naturais e as ciências do artificial se opõem. No entanto, elas se complementam, apenas possuem sentidos distintos. De fato, "[...] os artefatos não estão fora da natureza. Não tem qualquer permissão para ignorar ou violar as leis naturais." (SIMON, 1996, p. 24). Simon (1996) define o artificial como algo que foi produzido ou inventado pelo homem, sofrendo intervenções deste. Por consequência, máquinas, organizações, economia e aspectos da própria sociedade (como suas instituições) podem ser classificados como instâncias do artificial. Em outros termos, "O mundo em que vivemos hoje é muito mais artificial, fabricado pelo homem, do que natural [...]" (SIMON, 1996, p. 23).

Simon (1996) argumenta pela necessidade de criar uma ciência (i.e., um corpo de conhecimento rigoroso e validado) que se dedique a propor como construir artefatos que possuam certas propriedades desejadas - isto é, como projetá-los. Tal é uma "Ciência do Projeto", uma Design Science. "Ao projeto interessa o quê e como as coisas devem ser, a concepção de artefatos que realizem objetivos." (SIMON, 1996, p. 198). A missão principal da Design Science é, portanto, desenvolver conhecimento para a concepção e desenvolvimento de artefatos (VAN AKEN, 2004).

A partir do enfoque dado por uma Design Science, a problemática da relevância e da relação teoria-prática, constante do debate atual referido na seção inicial deste artigo, obtém novos contornos. Não se trata de um problema de transposição do conhecimento científico para o ambiente das organizações. A questão da relevância do conhecimento produzido e a tensão na relação teoria-prática exigem, na verdade, um novo foco de pesquisa: pesquisas efetivamente direcionadas ao projeto de artefatos que sustentem melhores soluções para os problemas existentes. Nesse sentido, Romme (2003) afirma que os estudos relacionados às organizações devem incluir a Design Science e a Design Science Research, como um dos principais modos de conceber o conhecimento e de realizar pesquisas científicas.

O conhecimento gerado a partir dos fundamentos da Design Science contribui também para o avanço no desenvolvimento da pesquisa com base em conhecimento do Tipo 2 (Mode 2). Por um lado, para Gibbons et al. (1994), a produção de conhecimento do Tipo 1 (Mode 1) é, essencialmente, acadêmica e aplicada a uma única disciplina. Por outro lado, o conhecimento do Tipo 2 (Mode 2) é multidisciplinar, e as pesquisas orientadas a esse tipo de conhecimento estão preocupadas em resolver problemas complexos relevantes, que consideram o contexto em que seus resultados serão aplicados (BURGOYNE; JAMES, 
2005). Por consequência, o conhecimento desenvolvido pela Design Science Research não é descritivoexplicativo, ele é prescritivo.

Alguns autores (VAN AKEN, 2004; ROMME, 2003; MANSON, 2006) distinguem a Design Science de outras perspectivas filosóficas e epistemológicas. Da perspectiva filosófica, para Cantamessa (2003, p. 2), a separação entre as ciências naturais e artificiais é semelhante à "[...] distinção aristotélica entre 'episteme' produzindo 'theoria' e a 'techne' com o objetivo de 'poieses' (isto é, produzindo coisas novas)". O Quadro 1 procura explicitar as principais comparações realizadas entre a Design Science Research e as outras perspectivas filosóficas e epistemológicas. Cabe registrar que a distinção que Van Aken (2004) faz entre as pesquisas orientadas à descrição e à prescrição é análoga à discussão entre as ciências natural e artificial.

De fato, a visão da ciência natural/social, aplicada à gestão, " [...] ajuda a entender o fenômeno organizacional, descobrindo as leis e forças que determinam suas características, funcionamento e resultados [...]" (ROMME, 2003, p. 558). As ciências humanas buscam representar, entender e refletir criticamente a respeito da experiência das pessoas que compõem a organização. Por sua vez, a Design Science seria responsável por conceber e validar sistemas que ainda não existem, seja criando, recombinando, alterando produtos/processos/softwares/ métodos para melhorar as situações existentes.

Segundo Romme (2003), o desenvolvimento de pesquisas organizacionais depende, significativamente, da criação de interfaces que favoreçam a comunicação e o senso de colaboração entre estes três enfoques de pesquisa. O Quadro 1 mostra contribuições de autores como Romme (2003), Van Aken (2004) e Manson (2006) no que tange à distinção entre a Design Science e as ciências tradicionais.

Enquanto a Design Science é a base epistemológica, a Design Science Research é o método que operacionaliza a construção do conhecimento nesse contexto (CHAKRABARTI, 2010). Para Vaishnavi e Kuechler (2009), a Design Science Research é um novo olhar ou um conjunto de técnicas analíticas que permitem o desenvolvimento de pesquisas nas diversas áreas, em particular na engenharia. A Design Science Research tem como objetivo estudar, pesquisar e investigar o artificial e seu comportamento, tanto do ponto de vista acadêmico quanto da organização (BAYAZIT, 2004). Nesse sentido, a Design Science Research se constitui em um processo rigoroso de projetar artefatos para resolver problemas, avaliar o que foi projetado ou o que está funcionando, e comunicar os resultados obtidos (ÇAĞDAŞ; STUBKJÆR, 2011).

A Design Science/Design Science Research tem amadurecido como abordagem principalmente na área de Tecnologia e Gestão da Informação (TREMBLAY;
HEVNER; BERNEDT, 2010; LEE; HUBONA, 2009; MARCH; SMITH, 2005; PEFFERS et al., 2008). Mas há também trabalhos no campo da gestão em geral, sob diferentes enfoques (VAN AKEN, 2004; MANSON, 2006; WORREN; MOORE; ELLIOTT, 2002; ROMME; DAMEN, 2007; ROMME, 2003; PLSEK; BIBBY; WHITBY, 2007; DENYER; TRANDFIELD; VAN AKEN, 2008; PANDZA; THORPE, 2010; XU; CHEN, 2011). Não há, entretanto, uma consolidação ou uma síntese geral dessas pesquisas e uma tentativa de sistematização, em sentido amplo, disponível. Cabe, portanto, proceder a uma proposição neste sentido.

A Design Science reconhece, de partida, que os problemas existentes nas organizações costumam ser específicos. Essa especificidade poderia inviabilizar um conhecimento passível de generalização. Com efeito, Van Aken (2004) argumenta que a generalização das prescrições, extensiva aos artefatos, precisa ser generalizável para uma "classe de problemas". Nesse sentido, uma vez estabelecido conceitualmente o que são a Design Science e a Design Science Research, é oportuno aprofundar o entendimento de seus principais elementos constituintes. Na sequência, procura-se definir conceitualmente o que são as "classes de problemas" e os "artefatos", objetos centrais do conhecimento em Design Science.

\section{Classes de problemas e artefatos}

Simon (1996) não define o que seria uma classe de problemas, embora as exemplifique. De fato, as "classes de problemas" podem consistir em uma organização para a trajetória e o desenvolvimento do conhecimento em uma Design Science. A própria natureza dos artefatos, como poderá ser observado nesta seção, pode induzir à conformação de tais classes. A principal discussão envolvendo a necessidade de definição das classes de problemas está em Van Aken (2004).

As classes de problemas permitem que os artefatos e, por consequência, suas soluções, não sejam apenas uma resposta pontual a certo problema em determinado contexto. "A Design Science não se preocupa com a ação em si mesma, mas com o conhecimento que pode ser utilizado para projetar as soluções." (VAN AKEN, 2004, p. 228). Nesse sentido, o conhecimento na Design Science é generalizável quando válido para uma dada classe de casos (VAN AKEN, 2004), aqui entendidos como uma classe de problemas. Entende-se, reforce-se, que o problema real, e, por consequência, os artefatos que geram soluções satisfatórias para este, é sempre singular em seu contexto. Contudo, tanto os problemas quanto as soluções satisfatórias podem compartilhar características comuns que permitam uma organização do conhecimento de uma dada Design Science por "classes de problemas" - habilitando assim a generalização e o avanço do conhecimento na área. 


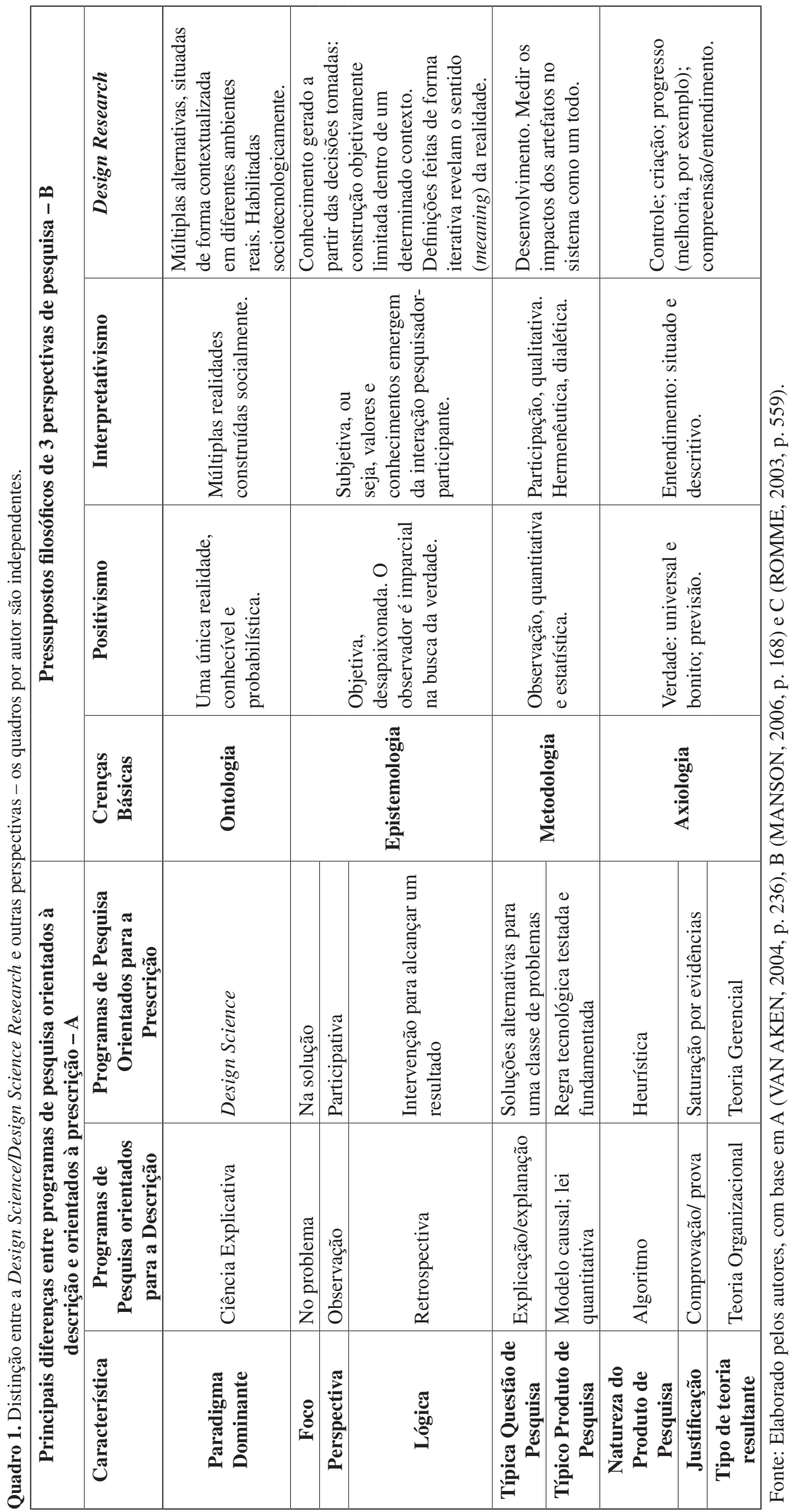




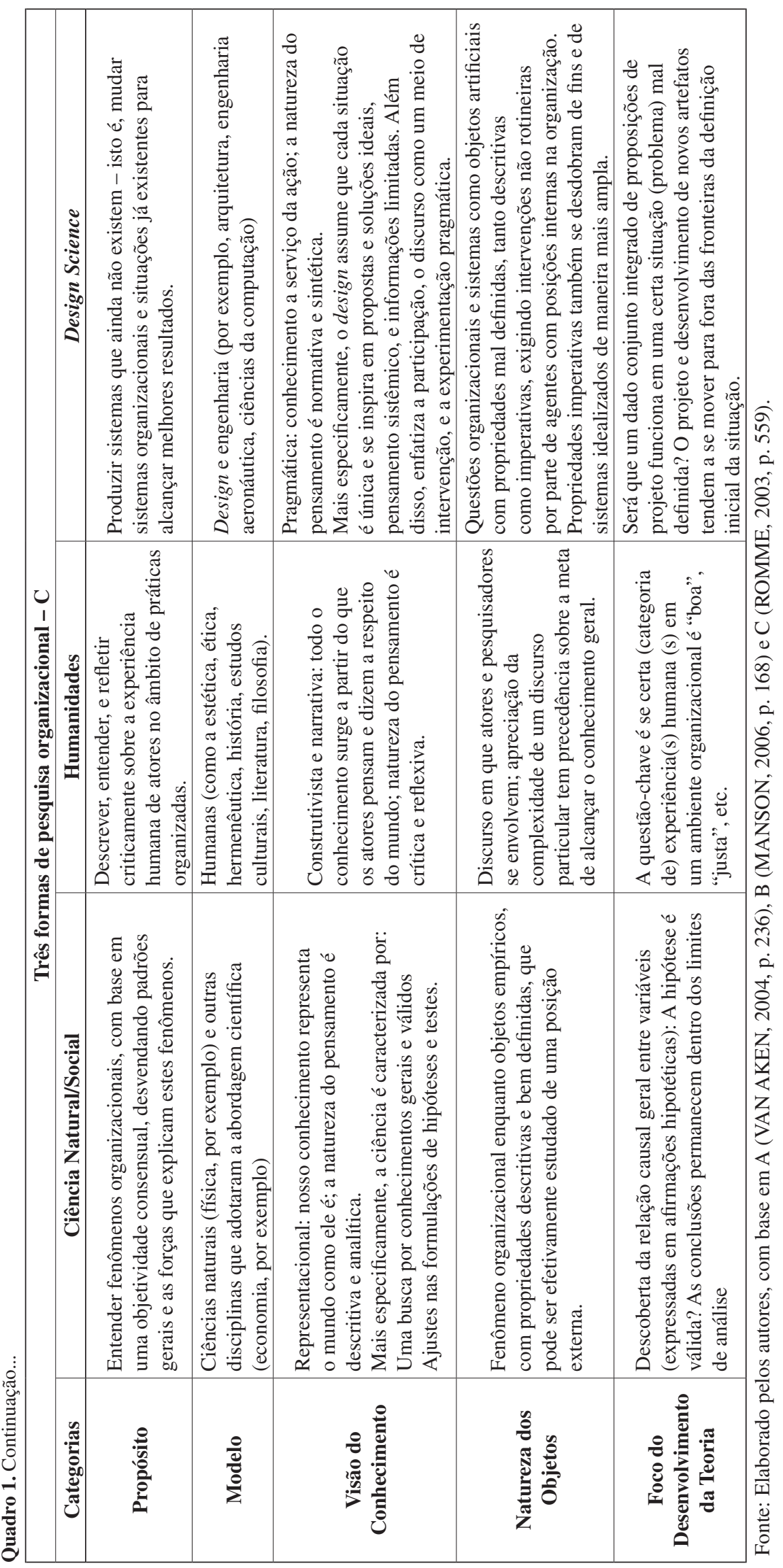


Não há uma definição conceitual da classe de problemas ou uma proposição para sua construção. Essa discussão, no entanto, parece central como uma alternativa apenas considerar soluções predominantemente pontuais. Dessa forma, define-se, neste artigo, "classe de problemas" como: a organização de um conjunto de problemas, práticos ou teóricos, que contenha artefatos avaliados, ou não, úteis para a ação nas organizações. O Quadro 2 é uma primeira tentativa, que procura exemplificar este conceito de classe de problemas.

Com o conceito de classe de problemas deixa-se aberta a possibilidade de tratamento de problemas teóricos, uma vez que um problema pode ser, inclusive, formas de testar uma teoria na prática organizacional. Também fica aberta a possibilidade de formalizar artefatos já existentes na prática de determinada organização, e que necessitam de avaliações em outros ambientes. Esse aspecto permite que os métodos tradicionais de pesquisa (Pesquisa-Ação, Estudo de Caso, Modelagem) sejam utilizados para a formalização de artefatos existentes.

Esses enquadramentos em termos de classes de problemas se assimila à aplicação de Sein et al. (2011).
Sein et al. (2011) consideram que a definição de classes de problemas deve ser realizada para favorecer a pesquisa, desde sua concepção até a generalização de seus resultados, visando a aplicação da solução não só para um problema em específico, mas sim para, justamente, uma certa classe de problemas. Para fins ilustrativos, cabe organizar uma lógica gráfica de definição de partida de classes de problemas. Essa tentativa se expressa na Figura 1.

A partir de um problema, teórico ou prático, identificado, é necessário conscientizar-se das repercussões para a organização de sua existência ou persistência. Além das repercussões, é necessário identificar quais objetivos ou metas seriam necessários para que o problema, transitoriamente, seja considerado satisfatoriamente resolvido. Esse procedimento consiste na "conscientização" e em um primeiro contorno do problema.

A partir dessa conscientização, é necessário realizar uma revisão sistemática na literatura (SILVA, 2009), com o objetivo de estabelecer o quadro de soluções empíricas conhecidas (SILVA; MENEZES, 2005). Esta 'revisão empírica' deve consistir na busca e identificação dos artefatos que procuram encaminhar

Quadro 2. Exemplos de Classes de Problemas e Artefatos.

\begin{tabular}{|c|l|}
\hline Classe de Problemas & \multicolumn{1}{c|}{ Artefatos } \\
\hline \multirow{3}{*}{ Planejamento e Controle da Produção } & Tambor-Pulmão-Corda (GOLDRATT, 1991) \\
\cline { 2 - 2 } & Jidoka/Kanban (OHNO, 1997) \\
\cline { 2 - 2 } & CONWIP (SPEARMAN; WOODRUFF; HOPP, 1990) \\
\hline \multirow{3}{*}{ Mensuração dos Custos } & Contabilidade de Ganhos (GOLDRATT, 1991) \\
\cline { 2 - 2 } & Custeio Baseado em Atividades (COOPER; KAPLAN, 1988) \\
\cline { 2 - 2 } & Unidades de Esforço de Produção (ALLORA, 1985) \\
\hline \multirow{4}{*}{ Alinhamento Estratégico } & Modelo de Labovitz e Rosansky (1997) \\
\cline { 2 - 2 } & Balanced Scorecard (KAPLAN; NORTON, 1992) \\
\cline { 2 - 2 } & Modelo de Hambrick e Cannella Junior (1989) \\
\cline { 2 - 2 } & Organizational Fitness Profiling (BEER; EISENSTAT, 1996, 2000) \\
\hline
\end{tabular}

Fonte: Elaborado pelos autores.

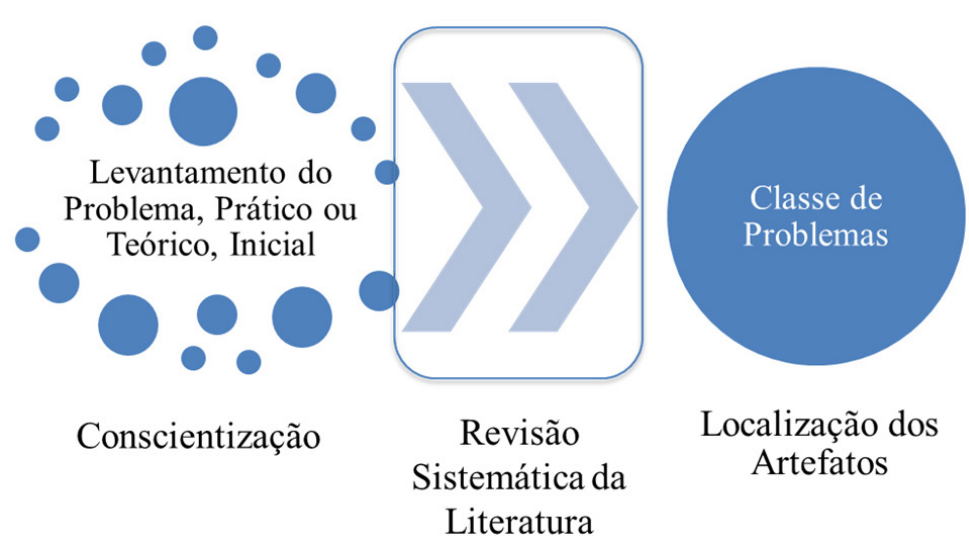

Figura 1. Lógica para Construção das Classes de Problemas. Fonte: Elaborado pelos autores. 
soluções ao problema em tela. Esse procedimento parece necessário, nesse momento, uma vez que seriam necessárias publicações que consolidassem as classes de problemas, os artefatos testados e suas soluções, como na medicina baseada em evidências, por exemplo (HUFF; TRANFIELD; VAN AKEN, 2006), ainda não disponíveis em outras áreas (como na Engenharia de Produção). Uma vez definidas as classes de problemas, é necessário caracterizar os artefatos associados.

Os artefatos são

[...] objetos artificiais que podem ser caracterizados em termos de objetivos, funções e adaptações. São normalmente discutidos, particularmente durante a concepção, tanto em termos imperativos como descritivos [...] (SIMON, 1996, p. 28).

Assim,

[...] o cumprimento de um propósito, ou adaptação a um objetivo, envolve uma relação de três elementos: o propósito ou objetivo; o caráter do artefato; e o ambiente em que ele funciona. (SIMON, 1996, p. 28).

Dessa forma,

[...] um artefato pode ser considerado como um ponto de encontro - interface - entre um ambiente interno, a substância e organização do próprio artefato, e um ambiente externo, [isto é], as condições em que o artefato funciona [...] (SIMON, 1996, p. 29).

Assim sendo, o artefato é a organização dos componentes do ambiente interno para atingir objetivos em um determinado ambiente externo (SIMON, 1996), como pode ser observado na Figura 2.

Uma vez definidos os artefatos, pode-se tipificá-los. Artefatos podem ser definidos como: Constructos, Modelos, Métodos e Instanciações (MARCH; SMITH, 1995). As descrições dos tipos de artefato podem ser observadas no Quadro 3. Dos tipos propostos para os artefatos, cabe aprofundar argumentos em relação aos métodos e à instanciação. Os métodos podem ser representados graficamente ou encapsulados em heurísticas e algoritmos específicos. Em sentido amplo, representam um conjunto de passos que devem ser obedecidos para que um resultado seja produzido em determinado ambiente externo.

Por sua vez, as instanciações são os artefatos que, em geral, geram maiores controvérsias em termos de sua definição. As instanciações informam como implementar ou utilizar determinado artefato e seus possíveis resultados. Nesse sentido, as instanciações podem se referir a um determinado artefato ou à articulação de diversos artefatos para a produção de um resultado em um contexto.

De certo ponto vista, as instanciações podem se assemelhar às prescrições heurísticas utilizadas por Van Aken (2004). Nesse sentido, as prescrições heurísticas expostas por Van Aken (2004) podem ser utilizadas como a forma de exprimir as instanciações.

Van Aken (2004, p. 227) apresenta a lógica de uma heurística prescritiva da seguinte forma: "Se você quer atingir $Y$ em uma situação $Z$, então você deve realizar a ação X". Analogamente, uma Instanciação significaria dizer: Se é necessário atingir Y (Objetivo da Instanciação), em uma situação Z (Ambiente Externo), então você deverá utilizar X (Construto, Modelo ou Método - incluindo a forma de colocar em prática).

$\mathrm{O}$ artefato Instanciação consiste no conjunto coerente de regras que orientam a utilização dos artefatos (constructos, modelos e métodos) em um determinado ambiente real. Esse ambiente real compreende desde as fronteiras da organização ou da indústria em que se encontra, até os contornos da realidade econômica que a organização está inserida. Assim, a Instanciação pode ter um papel particularmente relevante, pois orienta a utilização de outros artefatos considerando múltiplos fatores (economia, cultura organizacional e regional, contexto

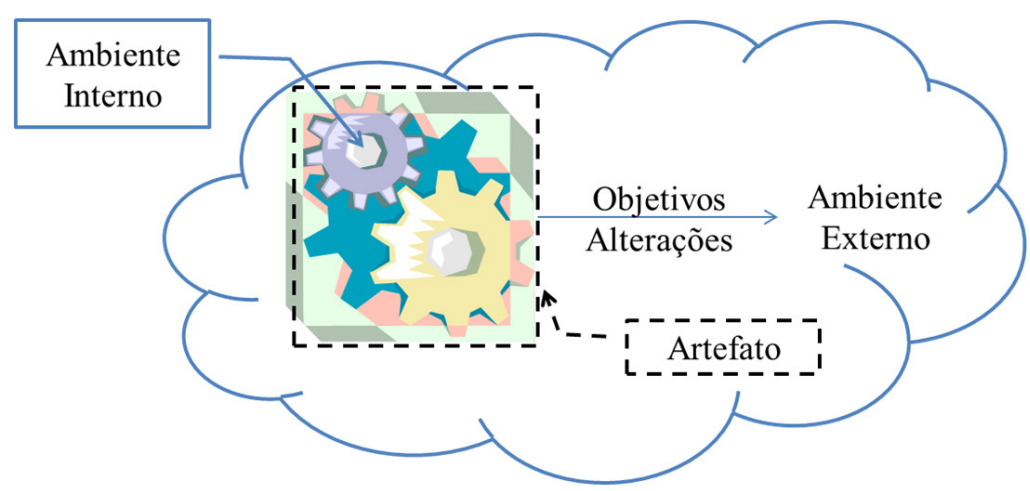

Figura 2. Caracterização do Artefato. Fonte: Concebida pelos autores com base em Simon (1996). 
Quadro 3. Tipos de Artefatos.

\begin{tabular}{|c|c|c|}
\hline & & Descrição \\
\hline \multirow{4}{*}{$\begin{array}{l}\text { Tipos de } \\
\text { Artefato }\end{array}$} & Constructos & $\begin{array}{l}\text { Constructos ou conceitos formam o vocabulário de um domínio. Eles constituem } \\
\text { uma conceituação utilizada para descrever os problemas dentro do domínio e para } \\
\text { especificar as respectivas soluções. Conceituações são extremamente importantes em } \\
\text { ambas as ciências, natural e de design. Eles definem os termos usados para descrever } \\
\text { e pensar sobre as tarefas. Eles podem ser extremamente valiosos para designers e } \\
\text { pesquisadores. }\end{array}$ \\
\hline & Modelos & $\begin{array}{l}\text { Um modelo é um conjunto de proposições ou declarações que expressam as relações } \\
\text { entre os constructos. Em atividades de design, modelos representam situações como } \\
\text { problema e solução. Ele pode ser visto como uma descrição, ou seja, como uma } \\
\text { representação de como as coisas são. Cientistas naturais muitas vezes usam o termo } \\
\text { 'modelo' como sinônimo de 'teoria', ou 'modelos' como as teorias ainda incipientes. } \\
\text { Na Design Science, no entanto, a preocupação é a utilidade de modelos, não a } \\
\text { aderência de sua representação à Verdade. Não obstante, embora tenda a ser impreciso } \\
\text { sobre detalhes, um modelo precisa sempre capturar a estrutura da realidade para ser } \\
\text { uma representação útil. }\end{array}$ \\
\hline & Métodos & $\begin{array}{l}\text { Um método é um conjunto de passos (um algoritmo ou orientação) usado para } \\
\text { executar uma tarefa. Métodos baseiam-se em um conjunto de constructos subjacentes } \\
\text { (linguagem) e uma representação (modelo) em um espaço de solução. Os métodos } \\
\text { podem ser ligados aos modelos, nos quais as etapas do método podem utilizar partes do } \\
\text { modelo como uma entrada que o compõe. Além disso, os métodos são, muitas vezes, } \\
\text { utilizados para traduzir um modelo ou representação em um curso para resolução de um } \\
\text { problema. Os métodos são criações típicas das pesquisas em Design Science. }\end{array}$ \\
\hline & Instanciações & $\begin{array}{l}\text { Uma instanciação é a concretização de um artefato em seu ambiente. Instanciações } \\
\text { operacionalizam constructos, modelos e métodos. No entanto, uma instanciação pode, } \\
\text { na prática, preceder a articulação completa de seus constructos, modelos e métodos. } \\
\text { Instanciações demonstram a viabilidade e a eficácia dos modelos e métodos que elas } \\
\text { contemplam. }\end{array}$ \\
\hline
\end{tabular}

Fonte: Extraído de March e Smith (1995, p. 257-258).

competitivo, histórico da organização) e o tempo/prazo para implementação. Uma vez expostas e definidas as classes de problemas e os artefatos, com sua tipologia, se avançará na explicitação do esquema de execução da pesquisa em Design Science - ou seja, para a condução da Design Science Research.

\section{A condução da Design Science Research}

Horváth (2004) faz uma revisão ampla das diversas perspectivas no campo da Design Science. Neste artigo, entretanto, serão expostas formas para a condução da Design Science Research. Cabe pontuar alguns aspectos relativos à Figura 3 , que consiste na articulação das contribuições, tal como destacado na legenda, de Takeda et al. (1990), Vaishnavi e Kuechler (2009), Manson (2006) e Peffers et al. (2008), evidenciando os passos do processo e suas principais saídas.

A etapa de Conscientização diz respeito à compreensão da problemática envolvida. Romme (2003) argumenta que pode ser necessário entender os problemas de uma perspectiva mais ampla, na qual o Pensamento Sistêmico (ANDRADE et al., 2006), por exemplo, poderia trazer uma contribuição relevante. O principal resultado da Conscientização é a definição e a formalização do problema a ser solucionado, suas fronteiras (ambiente externo) e as soluções satisfatórias necessárias. A Sugestão, segundo Manson (2006), está vinculada às atividades de desenvolver uma, ou mais, alternativas de artefato para a solução dos problemas. Por consequência, o resultado da Sugestão é o conjunto de possíveis artefatos e a escolha de um, ou mais, para serem desenvolvidos.

Conforme Manson (2006), a Sugestão é um processo essencialmente criativo, análogo ao processo de teorização, nas ciências naturais, em que "[...] diferentes pesquisadores podem gerar distintas teorias para um conjunto igual de observações [...]" (MANSON, 2006, p. 163). Logo, este processo pode ser considerado relativamente subjetivo e difícil de padronizar. Como o objetivo deste artigo é proporcionar uma visão geral sobre cada uma destas etapas, esta questão não será desenvolvida em profundidade. No entanto, sugere-se para esta etapa que protocolos sejam desenvolvidos, com o intuito de garantir a validade interna da pesquisa, evidenciar sua rastreabilidade. Nesse sentido, a fundamentação das escolhas deve ser explicitada. 


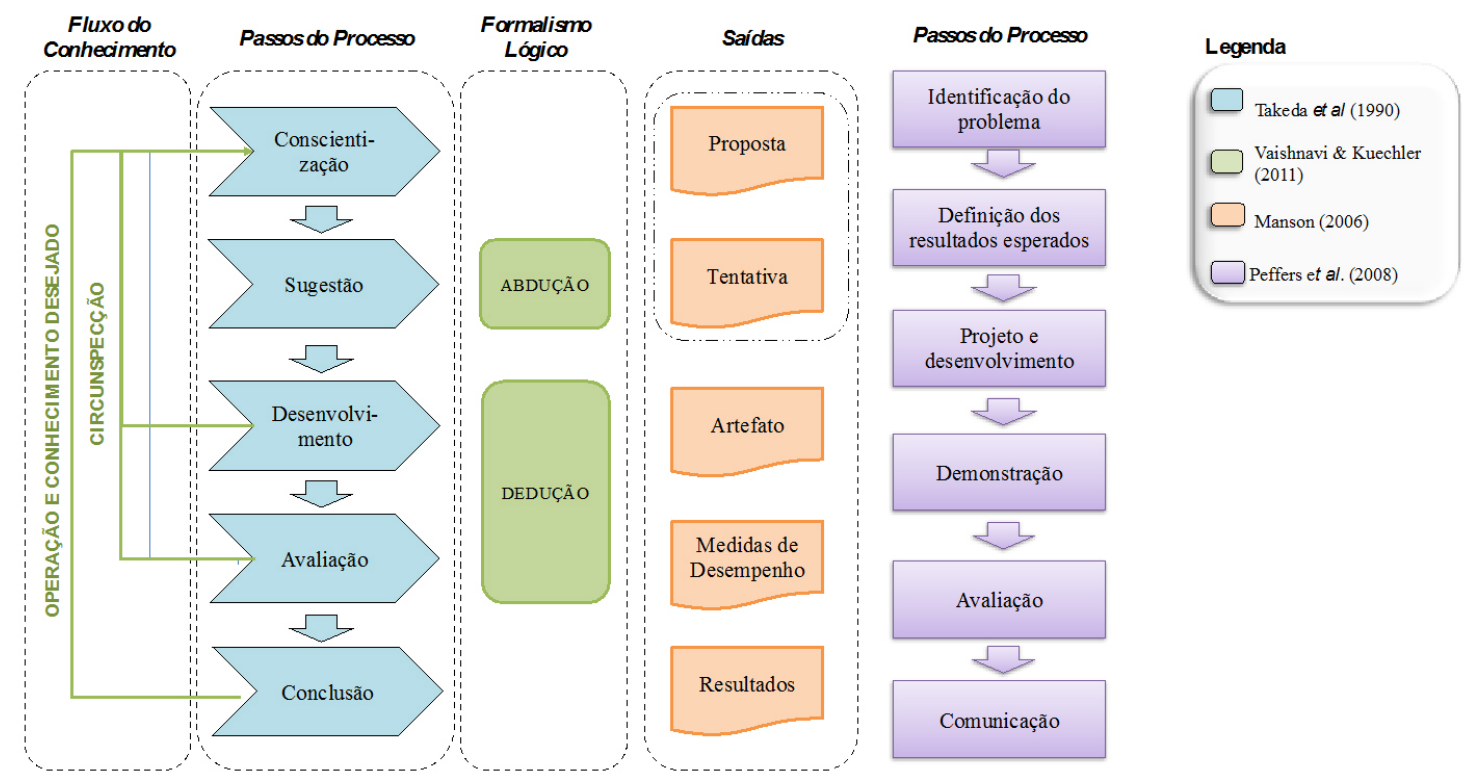

Figura 3. Esquema de condução da Design Science Research (TAKEDA et al., 1990; VAISHNAVI; KUECHLER, 2009; MANSON, 2006; PEFFERS et al., 2008).

Para a busca de uma solução para o problema, devem-se considerar alguns conceitos explicitados por Simon (1996). Simon (1996) faz uma distinção entre soluções ótimas (ideais) e soluções satisfatórias. Assim,

Uma decisão ótima em um modelo simplificado só raramente será ótima no mundo real. O tomador de decisão pode escolher entre decisões ótimas em um mundo simplificado ou decisões (suficientemente boas), que o satisfazem, num mundo mais próximo da realidade. (SIMON, 1996, p. 65).

Nesse sentido, buscam-se soluções suficientemente boas para problemas em que a solução ótima seja inacessível ou de implantação inviável (SIMON, 1996). Isso implica em definir quais os resultados satisfatórios. A definição de um resultado satisfatório pode ser obtida de duas formas: i) consenso entre as partes envolvidas no problema; ii) avanço da solução atual, comparativamente, às soluções geradas pelos artefato anteriores. Essa proposição se alinha ao delineamento proposto por Hevner (2007) de estabelecer a priori os critérios de aceitação das soluções. Os parâmetros para a aceitação das soluções precisam ser, portanto, justificados.

O Desenvolvimento corresponde ao processo de constituição do artefato em si (MANSON, 2006). Do ponto de vista de Simon (1996), é nesse momento que o pesquisador constrói o ambiente interno do artefato, uma vez que os objetivos e o ambiente externo foram caracterizados na Conscientização. Essa construção pode utilizar diferentes abordagens, tais como: algoritmos computacionais, representações gráficas, protótipos, maquetes em escala, entre outros. Assim sendo, o principal resultado do Desenvolvimento é $\mathrm{o}$ artefato em estado funcional.

Necessário frisar que quando se trata de Desenvolvimento, não se está referindo única e exclusivamente ao desenvolvimento de produtos. A Design Science Research pode servir para este fim, mas tem um objetivo mais amplo: gerar conhecimento que seja aplicável e útil para a solução de problemas, melhoria de sistemas já existentes e, ainda, criação de novas soluções e/ou artefatos (VENABLE, 2006).

Ademais, o conhecimento gerado, embora aplicado pontualmente na solução de problemas específicos, ou no desenvolvimento de novos artefatos, deve ser generalizável para o que foi definido como Classe de Problemas. Esta generalização permite a construção de um conhecimento útil - no sentido pragmático - não pontualmente, mas que possa ser ampla e efetivamente aplicável pela/para a sociedade (VENABLE, 2006; MARCH; SMITH, 1995; VAISHNAVI; KUECHLER, 2009).

A Avaliação é definida como o processo rigoroso de verificação do comportamento do artefato no ambiente para o qual foi projetado, em relação às soluções que se propôs alcançar. Uma série de procedimentos é necessária para verificar o desempenho do artefato.

O critério para validação do artefato se fundamenta na filosofia pragmática (WORREN; MOORE; ELLIOTT, 2002). Segundo Worren, Moore e Elliott (2002), uma teoria pragmaticamente válida contém três componentes principais. 
"O primeiro componente são proposições explícitas e causais: 'se você fizer A, então B é provável, em certas condições"; "O segundo componente consiste em regras que os profissionais podem usar para testar a validade destas afirmações causais"; "O terceiro componente informa que a teoria pragmática precisa conter declarações explícitas de como os resultados são criados". (WORREN; MOORE; ELLIOTT, 2002, p. 1233).

Esse raciocínio pode ser aplicado para avaliação da validade dos artefatos. Assim sendo, é necessário: i) explicitar o ambiente interno, o ambiente externo e os objetivos clara e precisamente; ii) explicitar como o artefato pode ser testado; e iii) descrever os mecanismos que medem os resultados.

Isso é importante, uma vez que os critérios de validade científica (rigor na concepção e condução da pesquisa) não garantem validade pragmática (eficácia e efetividade nas organizações). O principal resultado do processo de avaliação são as descrições anteriores e as medidas de desempenho alcançado como elemento último para comprovação da adequação do artefato.

Por sua vez, a Conclusão consiste na formalização geral do processo e sua comunicação às comunidades acadêmica e de profissionais. Esses aspectos podem ser sintetizados e instruções gerais para condução e avaliação da Design Science Research podem ser observadas no Quadro 4.

Por fim, o passo Comunicação, proposto por Peffers et al. (2008). Aqui se pode encontrar alguma dificuldade, em termos de divulgação no meio acadêmico. Isso decorre dos parâmetros atuais de avaliação para publicação estarem, mesmo em periódicos de Engenharia de Produção ou Gestão, arraigados aos paradigmas de pesquisa das ciências naturais. Não obstante, soluções bem sucedidas na prática, e métodos de projeto comprovadamente eficazes e efetivos, se difundem pelo tecido social e econômico por diversos percursos de comunicação, muitas vezes à revelia dos canais acadêmicos tradicionais.

Assim como Simon (1996) sugere que não existe qualquer contraposição entre as ciências naturais e a Design Science, como comentado anteriormente, também não existe tal tensão do ponto de vista da condução. March e Smith (1995) afirmam que as ciências naturais são compostas pela descoberta e a justificativa. A descoberta consiste na proposição de afirmações científicas por meio das teorias ou das leis.

Por sua vez, a justificativa é associada às atividades de teste dessas afirmações para garantir a validade. A Design Science é composta pela construção e pela avaliação. A construção é o processo de confecção de artefatos para um propósito específico, enquanto a avaliação é a verificação do desempenho dos artefatos como solução desejada (MARCH; SMITH, 1995). Segundo March e Smith (1995), tanto a descoberta, nas ciências naturais, quanto a construção ou concepção, na Design Science, não são processos bem compreendidos. Isso decorre do fato de serem processos eminentemente de criação.

Dessa forma, March e Smith (1995) argumentam para o uso conjunto de ambas as abordagens, de acordo com os objetivos de pesquisa. No Quadro 5, se explicita a comparação entre a Design Science Research e os paradigmas de pesquisa da ciência natural. O Quadro 5 foca nos parâmetros para avaliação de cada um dos artefatos, complementando a discussão em relação ao passo Avaliação apresentado na Figura 3. Além de March e Smith (1995) e Romme (2003) também

Quadro 4. Instruções Gerais para a Condução/Avaliação da Design Science Research.

\begin{tabular}{|c|l|}
\hline Instrução & \multicolumn{1}{c|}{ Descrição } \\
\hline Design como Artefato & $\begin{array}{l}\text { A pesquisa fundamentada em Design Science deve produzir um artefato viável, na forma } \\
\text { de um constructo, modelo, método e/ou uma instanciação. }\end{array}$ \\
\hline Relevância do Problema & $\begin{array}{l}\text { O objetivo da pesquisa fundamentada em Design Science é desenvolver soluções } \\
\text { baseadas em tecnologia para problemas gerenciais importantes e relevantes. }\end{array}$ \\
\hline Avaliação do Design & $\begin{array}{l}\text { A utilidade, qualidade e eficácia do artefato devem ser, rigorosamente, demonstradas por } \\
\text { meio de métodos de avaliação bem executados. }\end{array}$ \\
\hline Contribuições do Design & $\begin{array}{l}\text { Uma pesquisa fundamentada em Design Science deve prover contribuições claras e } \\
\text { verificáveis nas áreas específicas dos artefatos desenvolvidos, e apresentar fundamentação } \\
\text { clara em fundamentos de design e/ou metodologias de design. }\end{array}$ \\
\hline Rigor da Pesquisa & $\begin{array}{l}\text { A pesquisa em Design Science é baseada em uma aplicação de métodos rigorosos, tanto } \\
\text { na construção como na avaliação dos artefatos. }\end{array}$ \\
\hline $\begin{array}{c}\text { Design como um } \\
\text { Processo de Pesquisa }\end{array}$ & $\begin{array}{l}\text { A busca por um artefato eficaz e efetivo exige a utilização de meios que sejam } \\
\text { disponíveis, para alcançar os fins desejados, ao mesmo tempo que satisfaz as leis que } \\
\text { regem o ambiente em que o problema está sendo estudado. }\end{array}$ \\
\hline Comunicação da Pesquisa & $\begin{array}{l}\text { A pesquisa em Design Science deve ser apresentada tanto para o público mais orientado à } \\
\text { tecnologia quanto para aquele mais orientado à gestão. }\end{array}$ \\
\hline
\end{tabular}

Fonte: Adaptado de Hevner, March e Park (2004, p. 83). 


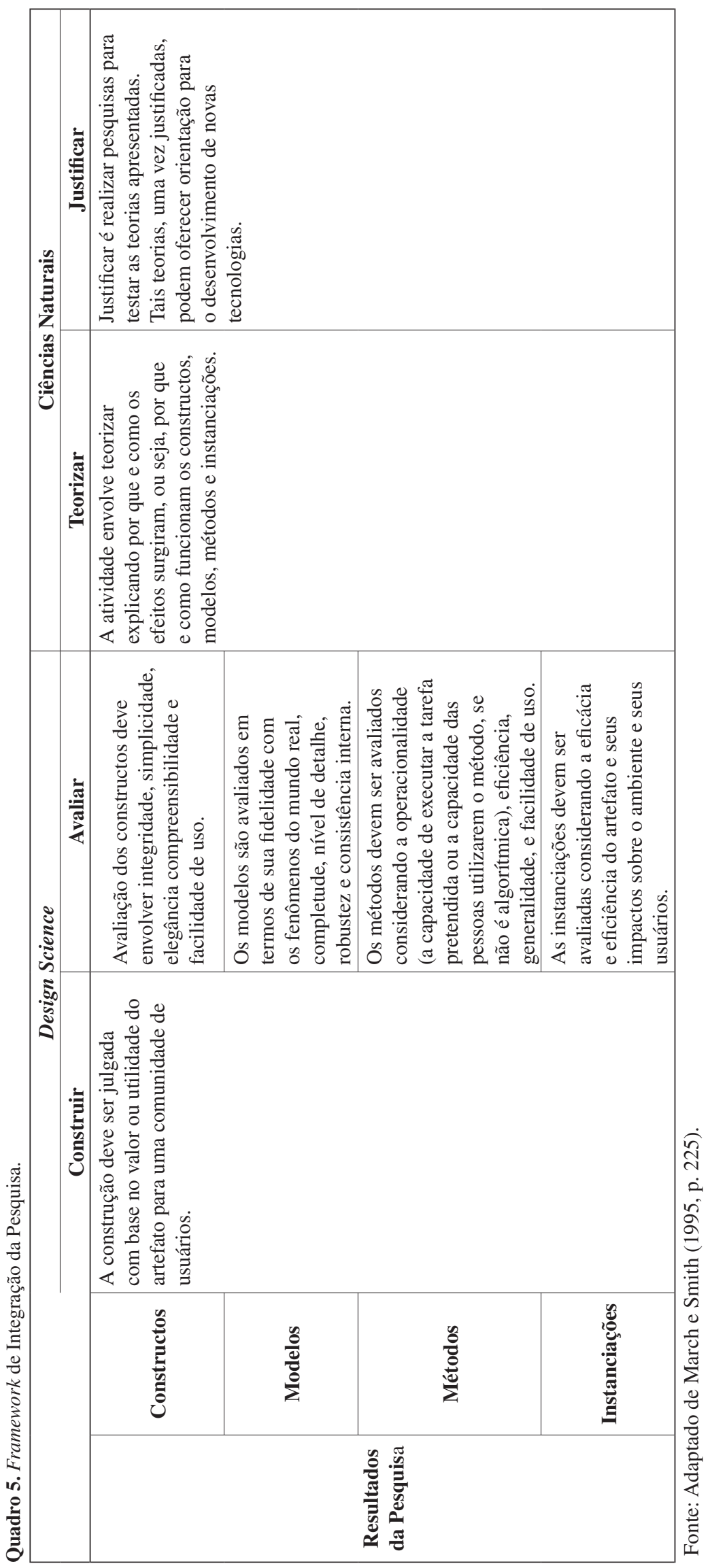


argumenta em relação às possibilidades e benefícios da integração desses paradigmas, no sentido de produzir conhecimentos explicativo e prescritivo (mutuamente) válidos.

Cabe retomar, brevemente, a discussão sobre Classes de Problemas. Na definição proposta, foi contemplada a flexibilidade em abranger artefatos avaliados, ou não. Tal flexibilidade procura incorporar a possibilidade de condução de pesquisas que procurem formalizar artefatos construídos diretamente pelas organizações, ou em conjunto, com pesquisadores. Dessa forma, trabalhos que formalizem soluções organizacionais na lógica de artefatos encontram abrigo nessa definição.

Van Aken (2004) argumenta, justamente, sobre a possibilidade do uso dos Estudos de Caso na formalização (explicitação estruturada) de artefatos que possam ser entendidos, formalizados e avaliados em diferentes contextos. Igualmente, a Pesquisa-Ação poderia atender a esse propósito, uma vez posicionada como instrumento sob o enfoque da Design Science. Portanto, Estudos de Caso e Pesquisa-Ação não são abordagens estranhas à Design Science Research, mas métodos de pesquisa que podem atender a objetivos distintos em função do enfoque que orienta o esforço de pesquisa. Esta combinação de métodos não é exclusividade da Design Science Research. É comum encontrar investigações que combinam métodos de pesquisa.

Não obstante, há certa confusão sobre as relações entre a Design Science Research, o Estudo de Caso e a Pesquisa-Ação, uma questão que se mostra particularmente aguda no contexto das tradições da Engenharia de Produção no Brasil. Nas seção a seguir, se procura demarcar as principais distinções entre as abordagens metodológicas do Estudo de Caso e da Pesquisa-Ação tradicionais, e as ambições e perspectivas da Design Science Research.

\section{Design Science Research, estudo de caso e pesquisa-ação}

O enquadramento metodológico de uma pesquisa não deve ser compreendido como um ato burocrático. $\mathrm{O}$ enquadramento metodológico consiste em escolher e justificar um método de pesquisa que permita, principalmente: i) responder ao problema de pesquisa formulado; ii) ser avaliado pela comunidade científica; iii) evidenciar procedimentos que robusteçam os resultados da pesquisa. Esses passos lógicos não devem ser vistos como dificultadores para a condução das pesquisas, mas como procedimentos necessários para assegurar a imparcialidade, o rigor na condução do trabalho e a confiabilidade dos resultados. A preocupação com o uso adequado dos métodos de pesquisa na área de gestão e de engenharia de produção tem se manifestado em uma série de trabalhos nacionais (MIGUEL, 2007; MELLO et al., 2011) e internacionais (ELLRAM, 1996; FORZA, 2002; COUGHLAN; COUGHLAN, 2002; VOSS; TSIKRIKTSIS; FROHLICH, 2002), que procuram recomendar procedimentos para condução das investigações.

Berto e Nakano (2000) relatam sobre o uso inapropriado do termo "Estudo de Caso".

Esse mesmo desvio foi encontrado em estudos onde se fez uso do rótulo para definir a coleta de dados em uma única organização, para a aplicação, comprovação ou validação de métodos ou modelos diversos. (BERTO; NAKANO, 2000, p.71).

No trecho destacado, entretanto, pode-se questionar onde haveria abrigo metodológico para pesquisas que construam modelos ou métodos, apliquem e avaliem em determinado contexto, sê assumido o cânone tradicional das Ciências Naturais. Pois, por um lado, é possível afirmar que tal procedimento não se enquadraria como um Estudo de Caso na compreensão de diversos autores (EINSENHARDT, 1989; ELLRAM, 1996; BERTO; NAKANO, 2000; YIN, 2005; MIGUEL, 2007).

Por outro lado, poder-se-ia argumentar, talvez, sobre a possibilidade de enquadrar metodologicamente tal tipo de investigação como uma Pesquisa-Ação. De fato, dentre as principais características da Pesquisa-Ação elencadas por Coughlan e Coughlan (2002, p. 224), são destacadas três: i) o pesquisador toma ação; ii) envolve dois objetivos: resolver um problema e contribuir para a ciência; iii) requer a interação (cooperação) entre pesquisadores e os participantes da pesquisa.

Ao se observar as características da Pesquisa-Ação tradicional, pode-se constatar a presença de elementos que sugerem que tal método serviria, em um primeiro momento, como alternativa de abordagem à Design Science Research. Na Design Science Research, entretanto, é necessário que o pesquisador avalie seu artefato. Essa avaliação pode, inclusive, ocorrer artificialmente como observam Iivari e Venable (2009), utilizando: i) simulação computacional; ii) experimentos em laboratório; iii) experimentos em campo. Tal possibilidade não é considerada na Pesquisa-Ação tradicional, uma vez que prescinde da verificação criteriosa do sucesso ou não da intervenção. Não há, também, necessidade explícita de contribuir para uma teoria de cunho prescritivo, pois o foco principal é a utilidade no caso singular em observação. Por fim, para os fins da Design Science Research, a interação, em algumas situações, pode ser necessária, mas não é essencial como na Pesquisa-Ação.

Como ponto de partida, parece necessário traçar algumas distinções entre o Estudo de Caso e a Pesquisa-Ação tradicionais, e a Design Science 
Research. O Quadro 6 não procura ser exaustivo, ele se constitui em uma contribuição no sentido de formalizar algumas distinções entre as abordagens aqui consideradas, não estabelecidas em pesquisas anteriores.

As principais distinções entre elas podem ser identificadas em termos de seus objetivos, a avaliação dos resultados, o papel do pesquisador e a necessidade de uma base empírica. Pesquisas que desenvolvam artefatos, os apliquem em um contexto organizacional (cooperativamente, ou não, com os envolvidos) e o avaliem, encontram na Design Science Research um respaldo metodológico apropriado. Esta é a agenda da Design Science Research, enquanto que o Estudo de Caso e a Pesquisa-Ação tradicionais se submetem, a princípio, às agendas das Ciências Naturais, Sociais e Humanas.

Embora este artigo esteja seguro quanto à distinção entre a agenda da Design Science Research e o caráter de método de pesquisa do Estudo de Caso e da Pesquisa-Ação, não há, de fato, consenso, em particular, sobre as fronteiras entre a Pesquisa-Ação e a Design Science Research na literatura. Järvinen (2007), por exemplo, compara a Pesquisa-Ação e a Design Science Research, e suas conclusões apontam para a similaridade entre essas abordagens metodológicas. Iivari e Venable (2009), por sua vez, apresentam uma reflexão que realiza distinções entre essas abordagens desde o ponto de vista dos pressupostos paradigmáticos de questões operacionais. Sein et al. (2011) propõem a integração entre essas abordagens no que denominam de Action Design Research ilustrando, inclusive, sua aplicação.

Pode-se buscar esclarecer essa discussão distinguindo, simplesmente, os fins (objetivos) e os meios de pesquisa. Por um lado, uma vez que os fins (objetivos) da pesquisa sejam descritivos, explicativos ou preditivos, pode-se inferir que o Estudo de Caso e Pesquisa-Ação, tal como tradicionalmente apresentados e defendidos, sejam abordagens

Quadro 6. Comparativo entre a Design Science Research, o Estudo de Caso e a Pesquisa-Ação.

\begin{tabular}{|c|c|c|c|}
\hline Características & Design Science Research & Estudo de Caso tradicional & Pesquisa-Ação tradicional \\
\hline \multirow[t]{2}{*}{ Objetivos } & $\begin{array}{l}\text { Desenvolver artefatos } \\
\text { que permitam soluções } \\
\text { satisfatórias aos problemas } \\
\text { práticos. }\end{array}$ & $\begin{array}{l}\text { Auxiliar na compreensão de } \\
\text { fenômenos sociais complexos. }\end{array}$ & $\begin{array}{l}\text { Resolver ou explicar } \\
\text { problemas de um determinado } \\
\text { sistema gerando conhecimento } \\
\text { para a prática e para a teoria. }\end{array}$ \\
\hline & Prescrever e Projetar & Explorar, Descrever e Explicar & Explorar, Descrever e Explicar \\
\hline Principais Atividades & $\begin{array}{l}\text { - Conscientizar } \\
\text { - Sugerir } \\
\text { - Desenvolver } \\
\text { - Avaliar } \\
\text { - Concluir }\end{array}$ & $\begin{array}{l}\text { - Definir Estrutura Conceitual } \\
\text { - Planejar o(s) caso(s) } \\
\text { - Conduzir Piloto } \\
\text { - Coletar Dados } \\
\text { - Analisar Dados } \\
\text { - Gerar Relatório } \\
\text { Miguel (2007,p. 221) }\end{array}$ & $\begin{array}{l}\text { - Planejar a Ação } \\
\text { - Coletar Dados } \\
\text { - Analisar dados e Planejar } \\
\text { - ações } \\
\text { - Implementar Ações } \\
\text { - Avaliar Resultados } \\
\text { - Monitorar (Contínuo) } \\
\text { Turrioni e Mello (2010) }\end{array}$ \\
\hline Resultados & $\begin{array}{l}\text { Artefatos (Constructos, } \\
\text { Modelos, Métodos, } \\
\text { Instanciações) }\end{array}$ & $\begin{array}{l}\text { Constructos } \\
\text { Hipóteses } \\
\text { Descrições } \\
\text { Explicações }\end{array}$ & $\begin{array}{l}\text { Constructos } \\
\text { Hipóteses } \\
\text { Descrições } \\
\text { Explicações } \\
\text { Ações }\end{array}$ \\
\hline $\begin{array}{l}\text { Tipo de } \\
\text { Conhecimento }\end{array}$ & $\begin{array}{l}\text { Como as coisas deveriam } \\
\text { ser }\end{array}$ & $\begin{array}{l}\text { Como as coisas são ou como } \\
\text { se comportam. }\end{array}$ & $\begin{array}{l}\text { Como as coisas são ou como } \\
\text { se comportam. }\end{array}$ \\
\hline Papel do Pesquisador & $\begin{array}{l}\text { Construtor e Avaliador do } \\
\text { Artefato }\end{array}$ & Observador & $\begin{array}{l}\text { Múltiplo, em função do Tipo } \\
\text { de Pesquisa-Ação }\end{array}$ \\
\hline Base Empírica & Não obrigatória & Obrigatória & Obrigatória \\
\hline $\begin{array}{l}\text { Colaboração } \\
\text { Pesquisador- } \\
\text { Pesquisado }\end{array}$ & Não obrigatória & Não obrigatória & Obrigatória \\
\hline Implementação & Não obrigatória & Não se Aplica & Obrigatória \\
\hline $\begin{array}{l}\text { Avaliação dos } \\
\text { Resultados }\end{array}$ & $\begin{array}{l}\text { Aplicações } \\
\text { Simulações } \\
\text { Experimentos } \\
\end{array}$ & Confronto com a Teoria & Confronto com a Teoria \\
\hline Abordagem & $\begin{array}{l}\text { Qualitativa e/ou } \\
\text { Quantitativa }\end{array}$ & Qualitativa & Qualitativa \\
\hline
\end{tabular}

Fonte: Elaborado pelos autores. 
adequadas. Por sua própria definição, entretanto, a Design Science Research não permite que tais objetivos sejam adequados.

Por outro lado, uma vez que os fins (objetivos) da pesquisa sejam prescritivos ou de desenvolvimento de tecnologias (artefatos), o raciocínio inverso não é verdadeiro. Para esse objetivo, a Design Science Research é a abordagem metodológica adequada. Nesse sentido, as abordagens do Estudo de Caso e da Pesquisa-Ação, caso sejam adaptados, podem se mostrar pertinentes para a consecução destes objetivos.

Estudos de Caso podem, quando o objetivo é prescritivo ou para o desenvolvimento de tecnologias (artefatos), ser úteis para compreender os artefatos existentes e em funcionamento em um determinado contexto. A formalização do ambiente interno, dos resultados que produz e do ambiente externo em que funciona, pode contribuir no avanço do conhecimento em Design Science. O fato de o artefato estar em uso e produzindo resultados superiores aos artefatos precedentes, nesse caso, pode informar a fase de avaliação.

Van Aken (2004) ilustra essa possibilidade do uso do Estudo de Caso na Design Science citando o reconhecido estudo de Womack, Jones e Roos (1990) sobre a indústria automobilística mundial. Nesse trabalho, foi formalizado um conjunto significativo de artefatos (métodos, instanciações) tais como: Kanban, sincronização da produção, a produção Just-in-Time, entre outros. Os Estudos de Caso, por consequência, cumprem dois objetivos: podem avançar o conhecimento teórico na área em pauta (isto é, ampliam o conhecimento de artefatos bem sucedidos diante de determinadas classes de problemas), e permitem formalizar artefatos eficazes que podem ser úteis a outras organizações.

A Pesquisa-Ação também pode contribuir, no contexto da Design Science, para a construção de artefatos em que: i) o desenvolvimento seja dependente da interação dos envolvidos na pesquisa; ii) a avaliação apenas possa ser realizada no contexto da empresa e/ou com a participação dos envolvidos na pesquisa. A Pesquisa-Ação, ainda, poderia ser particularmente utilizada para a geração de artefatos do tipo Instanciações, ou seja, relativamente à forma de aplicação dos artefatos na realidade. Portanto, argumenta-se em favor da possibilidade de utilização dessas abordagens metodológicas sob a perspectiva da Design Science - ou seja, de desenvolver conhecimentos que permitam a concepção e construção de artefatos. Dessa forma, admite-se a utilização de métodos mistos de pesquisa sob o enfoque da Design Science, ou seja, para o projeto de artefatos.

$\mathrm{Tal}$ aspecto parece importante para a ênfase em desenvolvimento tecnológico no âmbito da pesquisa em Engenharia de Produção. Não se trataria, em muitas situações, de argumentar pelo erro da abordagem por
Estudo de Caso em si, mas sim de questionar a agenda que rege a pesquisa em curso. Consciente de que se trata de desenvolver ou testar um dado artefato, o desenho do Estudo de Caso muda de configuração, e o cânone de rigor científico da Design Science pode ser acionado para orientar a montagem do protocolo adequado de pesquisa. Central, neste sentido, são os passos de avaliação e validade na Design Science Research.

\section{Avaliação e validade em Design Science Research}

Essa seção apresentará discussões relativas à Avaliação e Validação dos artefatos originados da Design Science Research. Cabe ressaltar que, para aumentar a confiabilidade nos resultados da pesquisa, é necessário um conjunto de cuidados e procedimentos rigorosos que minimizem o viés nos resultados obtidos e/ou nas soluções geradas. Dessa forma, a partir de uma filosofia pragmática, o artefato gerado deve sofrer uma série de avaliações, rigorosas, que possam demonstrar sua robustez.

Conforme Tremblay, Hevner e Berndt (2010), a pesquisa sustentada pela Design Science Research não pode estar preocupada somente com o desenvolvimento do artefato em si. Devem-se expor evidências de que o artefato, efetivamente, pode ser utilizado para resolver problemas reais (TREMBLAY; HEVNER; BERNDT, 2010).

A Avaliação final do artefato não dispensa que, em cada etapa do método da Design Science Research, sejam realizadas avaliações parciais dos resultados. Isso se faz necessário, para se certificar de que a pesquisa está no sentido dos objetivos propostos. Autores como Hevner, March e Park (2004) propõem alguns métodos que podem ser utilizados para a avaliação dos artefatos gerados pela Design Science Research, são eles (Quadro 7):

Outra forma de avaliação dos artefatos desenvolvidos poderia ser a utilização de Focus Group ou Grupo Focal. Segundo Bruseberg e McDonaghPhilp (2002), esta técnica poderia ser utilizada para suportar os desenvolvimentos. Bruseberg e McDonagh-Philp (2002) exemplificam que Grupos Focais foram aplicados na construção de softwares e avaliação de interfaces de softwares, por exemplo.

Os Grupos Focais poderiam ser utilizados como método de avaliação para a Design Science Research, uma vez que garantem uma discussão mais profunda e colaborativa em relação aos artefatos desenvolvidos pela pesquisa. De acordo com Bruseberg e McDonaghPhilp (2002), o Grupo Focal pode ser combinado com outras técnicas para: i) suportar as discussões dos grupos interessados; ii) facilitar a triangulação dos dados; e iii) auxiliar no surgimento de novas ideias a respeito de um determinado problema. 
Auxiliam, ainda, na realização da análise crítica dos resultados obtidos durante a pesquisa e que podem fazer brotar novas possibilidades com o intuito de encontrar melhores soluções para os problemas em estudo. Tremblay, Hevner e Berndt (2010) abordam dois tipos de Grupos Focais que poderiam ser utilizados para a avaliação dos artefatos desenvolvidos pela Design Science Research, estes tipos, bem como suas principais características estão explicitadas no Quadro 8.

A escolha do método de avaliação pode depender tanto do artefato desenvolvido quanto das exigências acerca da performance deste artefato. Por consequência, o método de avaliação deve estar alinhado diretamente ao artefato em si e a sua aplicabilidade. Além da avaliação a Design Science Research, também deve evidenciar rigor, desde o seu desenvolvimento até a sua avaliação.
Segundo Mentzer e Flint (1997), quando se trata de rigor é importante deixar claro que não está se referindo ao uso de métodos sofisticados. De fato, rigor implica cuidados para se evitar que algo seja afirmado, ou que se conclua algo que a pesquisa em si não tem condições de suportar. Migrando esse conceito para a Design Science Research, trata-se de demonstrar e justificar os procedimentos adotados para aumentar a confiabilidade do artefato e de seus resultados quando em uso.

Chakrabarti (2010) demonstra certa preocupação quando afirma que algumas maneiras de suportar a validação da pesquisa têm fundamentos empíricos insuficientes. A validade é um fator determinante para amparar a pesquisa, com o intuito de facilitar a utilização ou aplicação da pesquisa no campo prático (CHAKRABARTI, 2010). Conforme Mentzer e Flint (1997), a validade de uma pesquisa pode ser

Quadro 7. Métodos para avaliação dos artefatos.

\begin{tabular}{|c|l|}
\hline $\begin{array}{c}\text { Forma de } \\
\text { Avaliação }\end{array}$ & \multicolumn{1}{c|}{ Métodos propostos } \\
\hline Observacional & $\begin{array}{l}\text { Estudo de Caso: Estudar o artefato existente, ou não, em profundidade no ambiente de negócios. } \\
\text { Estudo de Campo: Monitorar o uso do artefato em projetos múltiplos. } \\
\text { Esses estudos podem, inclusive, fornecer uma avaliação mais ampla do funcionamento dos } \\
\text { artefatos configurando, dessa forma, um método misto de condução da pesquisa. }\end{array}$ \\
\hline Analítico & $\begin{array}{l}\text { Análise Estatística: Examinar a estrutura do artefato para qualidades estáticas. } \\
\text { Análise da Arquitetura: Estudar o encaixe do artefato na arquitetura técnica do sistema técnico geral. } \\
\text { Otimização: Demonstrar as propriedades ótimas inerentes ao artefato ou então demonstrar os } \\
\text { limites de otimização no comportamento do artefato. } \\
\text { Análise Dinâmica: Estudar o artefato durante o uso para avaliar suas qualidades dinâmicas } \\
\text { (por exemplo, desempenho). }\end{array}$ \\
\hline Experimental & $\begin{array}{l}\text { Experimento Controlado: Estudar o artefato em um ambiente controlado para verificar suas } \\
\text { qualidades (por exemplo, usabilidade). } \\
\text { Simulação: Executar o artefato com dados artificiais. }\end{array}$ \\
\hline Teste & $\begin{array}{l}\text { Teste Funcional (Black Box): Executar as interfaces do artefato para descobrir possíveis falhas e } \\
\text { identificar defeitos. } \\
\text { Teste Estrutural (White Box): Realizar testes de cobertura de algumas métricas para } \\
\text { implementação do artefato (por exemplo, caminhos para a execução). }\end{array}$ \\
\hline Descritivo & $\begin{array}{l}\text { Argumento informado: Utilizar a informação das bases de conhecimento (por exemplo, das } \\
\text { pesquisas relevantes) para construir um argumento convincente a respeito da utilidade do artefato. } \\
\text { Cenários: Construir cenários detalhados em torno do artefato, para demonstrar sua utilidade. }\end{array}$ \\
\hline
\end{tabular}

Fonte: Hevner, March e Park (2004, p. 86).

Quadro 8. Tipos de Grupos Focais em Design Science Research.

\begin{tabular}{|c|c|c|}
\hline Características & Grupo Focal Exploratório & Grupo Focal Confirmatório \\
\hline Objetivo & $\begin{array}{l}\text { Alcançar melhorias incrementais rápidas na } \\
\text { criação de artefatos. }\end{array}$ & $\begin{array}{l}\text { Demonstrar a utilidade dos artefatos } \\
\text { desenvolvidos no campo de aplicação. }\end{array}$ \\
\hline $\begin{array}{l}\text { Papel do Grupo } \\
\text { Focal }\end{array}$ & $\begin{array}{l}\text { Fornecimento de informações que possam } \\
\text { ser utilizadas para eventuais mudanças tanto } \\
\text { no artefato, como no roteiro do Grupo Focal. } \\
\text { - Refinamento do roteiro do Grupo Focal } \\
\text { e identificação de constructos a serem } \\
\text { utilizados em outros grupos. }\end{array}$ & $\begin{array}{l}\text { O roteiro de entrevistas previamente definido } \\
\text { para ser aplicado ao grupo de trabalho, não } \\
\text { deve ser modificado ao longo do tempo a } \\
\text { fim de garantir a possibilidade de se fazer } \\
\text { comparativos entre cada Grupo Focal } \\
\text { participante. }\end{array}$ \\
\hline
\end{tabular}

Fonte: Adaptado de Tremblay, Hevner e Berndt (2010). 
Quadro 9. Pontos a explicitar ao longo das etapas de condução de uma DSR.

\begin{tabular}{|c|c|c|}
\hline Etapa de Condução & Saídas da DSR & Pontos a Explicitar \\
\hline Conscientização & Proposta & $\begin{array}{l}\text { - Evidenciar a situação problemática } \\
\text { - Explicitar o ambiente externo e seus principais pontos de interação com } \\
\text { o artefato } \\
\text { - Explicitar as métricas e os critérios para a aceitação da solução do } \\
\text { artefato (quando não for possível a obtenção de uma solução ótima) } \\
\text { - Explicitar os atores que se interessam pelo artefato } \\
\text { - Explicitar as Classes de Problemas, os artefatos existentes e suas } \\
\text { limitações }\end{array}$ \\
\hline Sugestão & Tentativa & $\begin{array}{l}\text { - Explicitar as premissas e requisitos para a construção do artefato } \\
\text { - Registrar todas as tentativas de desenvolvimento do artefato } \\
\text { - Registrar as razões que fundamentaram a exclusão da tentativa de } \\
\text { artefato do Desenvolvimento } \\
\text { - Verificar possíveis implicações éticas da aplicação do artefato }\end{array}$ \\
\hline Desenvolvimento & Artefato & $\begin{array}{l}\text { - Justificar a escolha das ferramentas para o desenvolvimento do artefato } \\
\text { - Explicitar os componentes do artefato e as relações causais que geram o } \\
\text { efeito desejado para que o artefato realize seus objetivos } \\
\text { - Explicitar as formas pelas quais o artefato pode ser testado }\end{array}$ \\
\hline Avaliação & $\begin{array}{l}\text { Medidas de } \\
\text { Desempenho }\end{array}$ & $\begin{array}{l}\text { - Explicitar, em detalhes, os mecanismos de avaliação do artefato } \\
\text { - Evidenciar os resultados do artefato em relação às métricas inicialmente } \\
\text { projetadas } \\
\text { - No caso de avaliações qualitativas do artefato, explicitar as partes } \\
\text { envolvidas e as limitações de viés } \\
\text { - Evidenciar o que funcionou como o previsto e os ajustes necessários no } \\
\text { artefato }\end{array}$ \\
\hline Conclusão & Resultados & $\begin{array}{l}\text { - Sintetizar as principais aprendizagens em todas as fases do projeto } \\
\text { - Justificar a contribuição do trabalho para a Classe de Problemas em questão }\end{array}$ \\
\hline
\end{tabular}

Fonte: Elaborado pelos autores, a partir de Manson (2006).

caracterizada como um conjunto de procedimentos utilizados para garantir que o que foi concluído com uma pesquisa possa ser afirmado com segurança.

Em Design Science Research, se compreende como fonte de validade um conjunto de procedimentos para garantir que os resultados gerados pelo artefato provêm do ambiente interno projetado e o ambiente externo em que foi preparado para operar. Para isso é necessário: i) Explicitar o ambiente interno, o ambiente externo e os objetivos clara e precisamente; ii) Explicitar como o artefato pode ser testado; iii) Descrever os mecanismos que gerarão os resultados a serem controlados/acompanhados.

Para contribuir no sentido de explicitar os procedimentos adotados na pesquisa em Design Science Research, foi elaborado o Quadro 9. O Quadro 9 procura indicar os pontos a serem explicitados em cada uma das etapas e as saídas associadas, a partir das etapas de condução e saídas propostas por Manson (2006).

Procurou-se aqui sugerir mecanismos que permitam uma compreensão detalhada dos artefatos produzidos e, por consequência, garantam a replicação das pesquisas que fazem uso da Design Science Research. A replicação é um mecanismo importante para a consistência e teste do conhecimento produzido ao longo do tempo. Neste sentido, tal referência é centralmente importante para a adaptação adequada de métodos como o Estudo de Casos ou a Pesquisa-Ação para o contexto da Design Science.

\section{Considerações finais}

Este artigo procurou apresentar a Design Science, em geral, e a Design Science Research, em particular, para o ambiente da Engenharia de Produção e Gestão de Operações. Nesse sentido, foram demarcados seus principais conceitos, desdobrados seus passos metodológicos e delineadas suas distinções diante da discussão sobre métodos de pesquisa. Além disso, procurou-se explicitar alguns mecanismos que permitam a avaliação e reforcem a validade de uma pesquisa do tipo Design Science Research.

Este trabalho tem consciência de que sua contribuição se concentra na abertura da discussão dos aspectos metodológicos associados a outra forma de desenvolver as disciplinas que toma como foco. Busca ressaltar a necessidade, e abrir a possibilidade, de um conjunto amplo e importante de trabalhos que procurem avançar nessa temática, seja discutindo metodologias, seja praticando a pesquisa em Design. Outras contribuições importantes do trabalho, não observadas na literatura analisada, consistem em 
quatro pontos. Primeiro, há uma sistematização e organização da Design Science e da Design Science Research. Segundo, se apresentam algumas definições, não identificadas na literatura, sobre classes de problemas e instanciações. Terceiro, se procurou avançar no entendimento e formato das Instanciações, relevantes no contexto da Engenharia de Produção. Por fim, elaborou-se um primeiro quadro comparativo entre a Design Science Research, a Pesquisa-Ação e o Estudo de Caso.

Este trabalho, observe-se, foi desenvolvido no âmbito do programa Pró-Engenharias, financiado pela CAPES, no projeto Gestão de Operações em Organizações Inovadoras - GOOI. Este projeto tem a participação de vários programas de pós-graduação, a saber: PPGEPS/UNISINOS, PEP/COPPE/UFRJ, PEP-PE/UFPE, AI/INPI e Poli/USP. A Design Science Research foi vista como alternativa concreta de método para a condução de pesquisas de cunho tecnológico (tecnologias de gestão, por exemplo), constituindo-se em uma abordagem de rigor científico para colocar a inteligência universitária do País, nestas áreas, a serviço dos enormes desafios tecnológicos brasileiros.

Contudo, vários aspectos não puderam ser tratados e merecem atenção em pesquisas futuras. Primeiro, não foram discutidas as regras de projeto ou regras tecnológicas de um ponto de vista de orientação para a construção dos artefatos. Esse aspecto parece ser importante na medida em que pode formar uma base mais geral, que facilite o desenvolvimento dos artefatos e sua adequação ao ambiente externo. Segundo, a discussão sobre a Design Science Research e seus métodos concretos de condução ainda se encontra incipiente no debate dos artigos internacionais. Portanto, o presente trabalho é relevante também, pois aponta uma oportunidade para a comunidade científica brasileira participar como protagonista no processo de desenvolvimento do conhecimento para a área.

Terceiro, outros mecanismos de avaliação e validação precisam ser desenvolvidos para a consistência dos trabalhos e a aceitação dos trabalhos em Design Science Research como regidos por métodos científicos de pesquisa. Quarto, são necessárias mais pesquisas que assumam a Engenharia de Produção como uma Design Science, e conduzam pesquisas nos termos da Design Science Research. Quinto, este artigo abordou somente parte da Engenharia de Produção - aquela mais voltada à gestão - porém, é importante que sejam feitos novos estudos que sejam mais abrangentes. Seria importante também uma análise comparativa entre a Design Science Research e a Soft Systems Methodology (SSM).

Por fim, são necessários periódicos que consolidem as classes de problemas e os artefatos desenvolvidos pela comunidade científica, de forma a se constituírem em um mecanismo relevante para interação com o mundo vivo das organizações. De uma forma mais geral, trabalhos que revisem os métodos de construção de conhecimento em Engenharia precisam ser desenvolvidos. Está madura a necessidade de desenvolver uma "epistemologia da Engenharia", em particular da Engenharia de Produção. É a partir dessa discussão por uma pesquisa rigorosa, aplicada e relevante, que se poderá desenvolver tanto o conhecimento quanto a tecnologia necessária para o aumento da competitividade tecnológica brasileira, difundindo-os pelo tecido produtivo do País.

\section{Agradecimentos}

Os autores agradecem à CAPES (Coordenação de Aperfeiçoamento de Pessoal de Nível Superior) que, por meio do projeto MGOOI (Modelo de Gestão de Operações em Organizações Inovadoras) do Pró-Engenharias, suportou a reunião dos mais diversos especialistas, suscitando as discussões que fundamentaram e motivaram o desenvolvimento deste texto. Este projeto conta com a participação de representantes de diversos Programas de Pós-Graduação do Brasil, como os da COPPE/UFRJ, POLI/USP, UFPE, UNISINOS e do INPI.

\section{Referências}

ALLORA, F. Engenharia de Custos Técnicos. Blumenau: FURB, 1985.

ANDERY, M. A. et al. Para compreender a ciência: uma perspectiva histórica. Rio de Janeiro: Editora EDUC, 2004.

ANDRADE, A. L. et al. Pensamento Sistêmico: Caderno de Campo. Porto Alegre: Bookman, 2006.

BAYAZIT, N. Investigating Design: A Review of Forty Years of Design Research, Massachusetts Institute of Technology. Design Issues, v. 20, n. 1, p. 16-29, 2004. http://dx.doi.org/10.1162/074793604772933739

BEER, M.; EISENSTAT, R. A. Developing an organization capable of implementing strategy and learning, Human Relations, v. 49, n. 5, p. 597, 1996. http://dx.doi. org/10.1177/001872679604900504

BEER, M.; EISENSTAT, R. A. The silent killers of strategy implementation and learning. Sloan Management Review, v. 41, n. 4, p. 29-40, 2000.

BENBASAT, I.; WEBER, R. Research Commentary: Rethinking Diversity' in Information Systems Research. Information Systems Research, v. 7, n. 4, p. 389-399, 1996. http://dx.doi.org/10.1287/isre.7.4.389

BERTO, R. M. V. S.; NAKANO, D. N. Metodologia da pesquisa e a engenharia de produção. In: ENCONTRO NACIONAL DE ENGENHARIA DE PRODUÇÃO, 18., 1998, Niterói. Anais... Niterói, 1998.

BERTO, R. M. S.; NAKANO, D. N. A Produção Científica nos Anais do Encontro Nacional de Engenharia de Produção: Um Levantamento de Métodos e Tipos de Pesquisa. Produção, v. 9, n. 2, p. 65-76, 2000. http:// dx.doi.org/10.1590/S0103-65131999000200005

BRUSEBERG, A.; McDONAGH-PHILP, D. Focus groups to support the industrial/product designer: a review 
based on current literature and designers' feedback. Applied Ergonomics, v. 33, p. 27-38, 2002. http:// dx.doi.org/10.1016/S0003-6870(01)00053-9

BURGOYNE, J.; JAMES, K. T. Towards Best or Better Practice in Corporate Leadership Development: Operational Issues in Mode 2 and Design Science research. British Journal of Management, v. 17, p. 303-316, 2006. http://dx.doi. org/10.1111/j.1467-8551.2005.00468.x

ÇAĞDAŞ, V.; STUBKJÆR, E. Design research for cadastral systems. Computers, Environment and Urban Systems, v. 35, p. 77-87, 2011. http://dx.doi.org/10.1016/j. compenvurbsys.2010.07.003

CANTAMESSA, M. An empirical perspective upon design research. Journal Engineering Design, v. 14, n. 1, p. 1-15, 2003. http://dx.doi. org/10.1080/0954482031000078126

CHAKRABARTI, A. A course for teaching design research methodology. Artificial Intelligence for Engineering Design, Analysis and Manufacturing, v. 24, p. 317-334, 2010. http://dx.doi.org/10.1017/ S0890060410000223

COOPER, R.; KAPLAN, R. S. Measure costs right: Make the right decisions. Harvard Business Review, p. 96-104, Sept/Oct 1988.

COUGHLAN, P.; COUGHLAN, D. Action Research for Operations Management. International Journal of Operations \& Production Management, v. 22, n. 2, p. 220-240, 2002. http://dx.doi. org/10.1108/01443570210417515

GOLDRATT, E. M. A Síndrome do palheiro: Garimpando informações num oceano de dados. São Paulo: C. Fulmann, 1991.

GOUVÊA DA COSTA, S. E.; PINHEIRO DE LIMA, E. Processos: Uma Abordagem da Engenharia para a Gestão de Operações. In: MIGUEL, P. A. C. et al. Metodologia de Pesquisa em Engenharia de Produção e Gestão de Operações. Rio de Janeiro: Campus, 2011. cap. 4, p. 63-72.

CRAIGHEAD, C. W.; MEREDITH, J. M. Operations management research: evolution and alternative future paths, International Journal of Operations \& Production Management, v. 28, n. 8, p. 710-726, 2008. http://dx.doi.org/10.1108/01443570810888625

DENYER, D.; TRANDFIELD, D.; VAN AKEN, J. E. Developing Design Propositions through Research Synthesis. Organization Studies, v. 29, n. 3, p. 393-413, 2008. http://dx.doi. org/10.1177/0170840607088020

EINSENHARDT, K. M. Building theories from case study research. Academy of Management Review, v. 14, p. 532-550, 1989.

ELLRAM, L. M. The use of the case study method in logistics research. Journal of Business Logistics, v. 17, n. 2, p. 93-138, 1996.

FORD, E. et al. A Pesquisa que faz a diferença. RAE Revista de Administração de Empresas, v. 43, n. 4, p. 86-101, 2003.

FORZA, C. Survey research in operations management: a process-based perspective. International Journal of Operations \& Production Management, v. 22, n. 2, p. 152-194, 2002. http://dx.doi. org/10.1108/01443570210414310

GIBBONS, M. et al. The New Production of Knowledge: The dynamics of science and research in contemporary societies. London: Sage Publications, 1994.

GUIDE, V. D. R.; VAN WASSENHOVE, L. N. Dancing with the Devil: Partnering with Industry but Publishing in Academia. Decision Sciences, v. 38, n. 4, p. 531-546, 2007. http://dx.doi. org/10.1111/j.1540-5915.2007.00169.x

HAMBRICK, D. C. The Field of Management's Devotion to Theory: Too Much of a Good Thing? Academy of Management Journal, v. 50, n. 6, p. 1346-1352, 2007. http://dx.doi.org/10.5465/AMJ.2007.28166119

HAMBRICK, D. C.; CANNELLA JUNIOR, A. A. Strategy implementation as substance and selling. Academy of Management Executive, v. 3, n. 4, p. 278-285, 1989. http://dx.doi.org/10.5465/AME.1989.4277401

HEVNER, A. R.; MARCH, S.T.; PARK, J. Design Science in Information Systems Research. MIS Quaterly, v. 28, n. 1, p. 75-105, 2004.

HEVNER, A. R. A Three Cycle View of Design Science Research. Scandinavian Journal of Information Systems, v. 19, n. 2, p. 87-92, 2007.

HORVÁTH, I. A treatise on order in engineering design research. Research in Engineering Design, v. 15, p. 155-181, 2004. http://dx.doi.org/10.1007/ s00163-004-0052-X

HUFF, A.; TRANFIELD, D.; VAN AKEN, J. E., Management as a Design Science Mindful of Art and Surprise. Journal of Management Inquiry, v. 15, n. 4, p. 413-424, 2006. http://dx.doi.org/10.1177/1056492606295900

IIVARI, J.; VENABLE, J. Action Research and Design Science Research - Seemingly Similar but Decisively Dissimilar. In: EUROPEAN CONFERENCE ON INFORMATION SYSTEMS, 17., 2009, Verona. Proceedings... Verona, 2009. p. 1- 13.

JÄRVINEN, P. Action Research is Similar to Design Science. Quality \& Quantity, v. 41, p. 37-51, 2007. http://dx.doi.org/10.1007/s11135-005-5427-1

KAPLAN, R.; NORTON, D. P. The Balanced Scorecard: measures that drive performance. Harvard Business Review, v. 70, n. 1, p. 71-86, 1992. PMid:10119714.

LABOVITZ, G.; ROSANSKY, V. The power of alignment: how great companies stay centered and accomplish extraordinary things. EUA: John Wiley \& Sons, 1997.

LEE, A. S.; HUBONA, G. S. A Scientific Basis for Rigor in Information Systems Research. MIS Quaterly, v. 33, n. 2, p. 237-262, 2009.

MANSON, N. J. Is operations research really research? Orion, v. 22, n. 2, p. 155-180, 2006. http://dx.doi. org/10.5784/22-2-40

MARCH, S. T.; SMITH, G. F. Design and natural science research in Information Technology. Decision Suport Systems, v. 15, p. 251-266, 1995. http://dx.doi. org/10.1016/0167-9236(94)00041-2

MENTZER, J. T.; FLINT, D. J. Validity in Logistics Research. Journal of Business Logistics, v. 18, n. 1, p. 199-216, 1997.

MIGUEL, P. A. C. Estudo de caso na engenharia de produção: estruturação e recomendações para sua 
condução. Produção, v. 17, n. 1, p. 216-229, 2007. http://dx.doi.org/10.1590/S0103-65132007000100015

MELLO, C. H. P. et al. Pesquisa-ação na engenharia de produção: proposta de estruturação para sua condução. Produção, v. 22, n. 1, p. 1-13, 2011. http://dx.doi. org/10.1590/S0103-65132011005000056

NAKANO, D. Métodos de Pesquisa Adotados na Engenharia de Produção e Gestão de Operações. In: MIGUEL, P. A. C. et al. Metodologia de Pesquisa em Engenharia de Produção e Gestão de Operações. Rio de Janeiro: Campus, 2010. cap. 4, p. 63-72.

OHNO, T. O Sistema Toyota de Produção: Além da Produção em Larga Escala. Porto Alegre: Bookman, 1997.

PANDZA, K.; THORPE, R. Management as Design, but What Kind of Design? An Appraisal of the Design Science Analogy for Management. British Journal of Management, v. 21, p. 171-186, 2010. http://dx.doi. org/10.1111/j.1467-8551.2008.00623.x

PEFFERS, K. et al. A Design Science Research Methodology for Information Systems Research. Journal of Management Information Systems, v. 24, n. 3, p. 45-77, 2008. http://dx.doi.org/10.2753/ MIS0742-1222240302

PLATTS, K. W. A Process Approach to Researching Manufacturing Strategy. International Journal of Operations \& Production Management, v. 13, n. 8, p. $4-17,1993$. http://dx.doi. org/10.1108/01443579310039533

PLATTS, K. W. et al. Testing manufacturing strategy formulation processes. International Journal of Production Economics, v. 56-57, p. 517-523, 1998.

PLSEK, P.; BIBBY, J.; WHTIBY, E. Practical Methods for Extracting Explicit Design Rules Grounded in the Experience of Organizational Managers. Journal of Applied Behavioral Science, v. 43, n. 1, p. 153-170, 2007. http://dx.doi.org/10.1177/0021886306297013

POPPER, K. A Lógica da Pesquisa Científica. São Paulo: Cultrix, 2006.

ROMME, A. G. L.; DAMEN, I. C. M. Toward ScienceBased Design in Organization Development. The Journal of Applied Behavioral Science, v. 43, n. 1, p. 108-121, 2007. http://dx.doi. org/10.1177/0021886306297011

ROMME, A. G. L. Making a difference: Organization as Design. Organization Science, v. 14, n. 5, p. 558-573, 2003. http://dx.doi.org/10.1287/ orsc. 14.5.558.16769

RYNES, S. L.; BARTUNEK, J. M.; DAFT, R. L. Across the Great Divide: Knowledge Creation and Transfer between Practitioners and Academics. Academy of Management Journal, v. 44, n. 2, p. 340-355, 2001. http://dx.doi.org/10.2307/3069460

SEIN, M. K. et al. Action Design Research. MIS Quaterly, v. 35, n. 1, p. 37-56, 2011.

SILVA, E. L.; MENEZES, E. M. Metodologia da pesquisa e elaboração de dissertação. 4. ed. Florianópolis: UFSC, 2005.

SILVA, E. R. P. Métodos para Revisão e Mapeamento Sistemático da Literatura. Rio de Janeiro: Escola Politécnica de Engenharia, Universidade Federal do Rio de Janeiro, 2009. Projeto de Graduação.
SIMON, H. A. The Sciences of the Artificial. Cambridge: MIT Press, 1969

SIMON, H. A. The Sciences of the Artificial. 3rd ed Cambridge: MIT Press, 1996.

SLACK, N.; LEWIS, M.; BATES, H. The two worlds of operations management research and practice: Can they meet, should they meet? International Journal of Operations \& Production Management, v. 24, n. 4, p. 372-387, 2009. http://dx.doi. org/10.1108/01443570410524640

SPEARMAN, M. L.; WOODRUFF, D. L.; HOPP, W. J. CONWIP - a pull alternative to KANBAN. International Journal of Production Research, v. 28, n. 5, p. 879-894, 1990. http://dx.doi. org/10.1080/00207549008942761

STARKEY, K.; MANDAN, P. Bridging the Relevance Gap: Aligning Stakeholders in the Future of Management Research. British Journal of Management, v. 12, p. S3-S26, 2001. Special Issue. http://dx.doi. org/10.1111/1467-8551.12.s1.2

TAKEDA, H. et al. Modeling Design Process. AI Magazine, v. 11, n. 4, p. 37-48,1990.

TAYLOR, A.; TAYLOR, M. Operations management research: contemporary themes, trends and potential future directions. International Journal of Operations \& Production Management, v. 29, n. 12, p. 1316-1340, 2009. http://dx.doi. org/10.1108/01443570911006018

THIOLLENT, M.; ALVEAR, C. A. S. Sobre o papel do engenheiro de produção em projetos sociais. In: SIMPÓSIO DE ENGENHARIA DE PRODUÇÃO - SIMPEP, 16., 2009, Bauru. Anais... Bauru, 2009.

TREMBLAY, M. C.; HERVNER, A. R.; BERNDT, D. J, Focus Groups for Artifact Refinament and Evaluation in Design Research. Communications of the Association for Information Systems, v. 26, n. 27, p. 599-618, 2010.

TURRIONI, J. B.; MELLO, C. H. P. Pesquisa-Ação na Engenharia de Produção. In: MIGUEL, P. A. C. et al. Metodologia de Pesquisa em Engenharia de Produção e Gestão de Operações. Rio de Janeiro: Campus, 2010. cap. 7, p. 146-163.

VAISHNAVI, V.; KUECHLER, W. Design Research in Information Systems. 2009. Disponível em: <http:// desrist.org/design-research-in-information-systems $>$. Acesso em: 18 out. 2011.

VAN AKEN, J. E. Management Research as a Design Science: Articulating the Research Products of Mode 2 Knowledge Production in Management. British Journal of Management, v. 16, p. 19-36, 2005. http://dx.doi. org/10.1111/j.1467-8551.2005.00437.x

VAN AKEN, J. E. Management Research Based on the Paradigm of the Design Sciences: The Quest for FieldTested and Grounded Technological Rules. Journal of Management Studies, v. 41, n. 2, p. 219-246, 2004. http://dx.doi.org/10.1111/j.1467-6486.2004.00430.x

VENABLE, J. R. The Role of Theory and Theorising in Design Science Research. DESRIST, v. 24-25, p. 1-18, 2006.

VOSS, C.; TSIKRIKTSIS, N.; FROHLICH, M. Case Research in Operations Management, International Journal of Operations \& Production Management, 
v. 22, n. 2, p. 195-219, 2002. http://dx.doi. org/10.1108/01443570210414329

XU, L.; CHEN, J. Technological Rules Based Business Models Analysis: A Design Science Approach. International Journal of Business and Management, v. 6, n. 9, p. 113-121, 2011. http://dx.doi.org/10.5539/ ijbm.v6n9p113

WORREN, N.; MOORE, K.; ELLIOTT, R. When Theories become tools: Toward a Framework for Pragmatic Validity.
Human Relations, v. 55, n. 10, p. 1227-1250, 2002. http://dx.doi.org/10.1177/0018726702055010082

WOMACK, J. P.; JONES, D. J.; ROOS, D. The Machine that Changed the Word: How Japan's Secret Weapon in the Global Auto War Will Revolutionize Western Industry: The Story of Lean Production. New York: Harper Perennial, 1990.

YIN, R. K. Estudo de caso: Planejamento e métodos. 3. ed. Porto Alegre: Bookman, 2005. 
